\title{
Staatlicher Strafanspruch und Strafzwecke
}

\author{
MICHAEL PAWLIK
}

I. Das Ärgernis des Strafzwanges

II. Präventionstheoretische Strafbegründungen

1. Die Attraktivität des Präventionsdenkens

2. Die negative Generalprävention

3. Die Spezialprävention

4. Die positive Generalprävention

III. Vergeltung als Strafzweck

1. Strafe als Schadenersatz

2. Verbrecherisches Unrecht als Mitwirkungspflichtverletzung

3. Legitimationsgrund der Mitwirkungspflicht: Aufrechterhaltung eines Zustandes der Freiheitlichkeit

4. Strafe und Schmerz

\section{Das Ärgernis des Strafzwanges}

„Nirgend manifestirt sich die Majestät des Staates so sehr als in der Strafe, aber nirgend manifestirt sich auch so sehr, daß seine Macht von oben ertheilt ist, und nicht von Menschen. "1 Mit diesen Worten eröffnet FRIEDRICH JULIUS STAHL, der konservative preußische Staatsdenker, seine straftheoretischen Erörterungen. Die staatliche Strafe ist ein so grundstürzender Eingriff, dass für STAHL schon allein ihretwegen der Staat nur durch göttliche Einsetzung legitimierbar ist. Die Antwort STAHLS ist einem säkularen Rechtsdenken verschlossen. Die Schärfe seines Problembewusstseins ist dagegen bis heute beispielhaft. Was berechtigt den Staat dazu, einzelnen seiner Bürger, gestützt auf den Vorwurf eines massiven Fehlverhaltens, zwangsweise fundamentale Güter zu entziehen; kurz: weshalb darf der Staat strafen? Diese Frage bildet nach wie vor einen der schmerzlichsten Stachel im Fleisch einer jeden freiheitlichen Rechtsordnung, und deshalb kann der moderne Verfassungsstaat gar nicht anders, als der staatlichen Strafgewalt mit beträchtlicher Skepsis, gleichsam einem Grundmisstrauen, zu begegnen.

Wer sich der Frage nach der Legitimität der Kriminalstrafe widmet, operiert nicht im luftleeren Raum. Die Strafe ist keine Erfindung der Theorie. „Das Wort und die Sache waren“ in den Worten FEUERBACHS „lange vor der

1 Friedrich Julius Stahl, Die Philosophie des Rechts, Bd. II/2 (Die Staatslehre und die Principien des Staatsrechts), 5. Aufl. 1878, Nachdruck 1963, S. 682. 
Wissenschaft, in welcher der darauf bezeichnete Begriff dargestellt werden soll, vorhanden. “2 Um den Begriff der Strafe dingfest zu machen, ist deshalb, so FEUERBACH weiter, ,,der Sprachgebrauch [...] unser erster und einziger Führer, und die Analysis desselben das Fundamentalgeschäft in dieser Untersu-

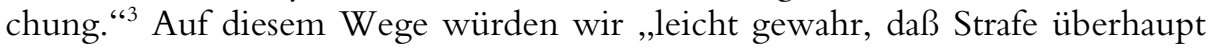
ein Uebel bedeute, welches um begangener gesetzwidriger Handlungen [...] einem Subjecte zugefügt wird. “" Dass das soziale Phänomen, welches wir Kriminalstrafe nennen, an eine vorangegangene, rechtlich missbilligte Tat des Bestraften anknüpft, der „Realgrund“ der Strafe ${ }^{5}$ also in der Vergangenheit liegt, wird auch heute allgemein anerkannt. ${ }^{6}$ Von der Klärung des Begriffs der Strafe ist FEUERBACH zufolge freilich die ,ganz andere Frage“ zu unterscheiden, „ob dieser Begriff eine rechtliche Realität habe? ob es ein Recht, ein solches Uebel zuzufuigen, gebe?"7 Einige Stationen auf der Suche nach dem „Rechtsgrund“ der Strafe ${ }^{8}$ möchte ich nachfolgend vorstellen.

Zur Beantwortung der Rechtsgrundfrage stehen zwei unterschiedliche Deutungsschemata zur Verfuigung: Entweder wir fassen die Straftat als Gefahr auf - als ein Verhalten, ,das als solches gewissermaßen den Keim der Wiederholbarkeit in sich trägt, sei es durch denselben Täter, sei es aufgrund der Nachahmung durch andere. "9 Oder aber wir interpretieren sie als Verbrechen - als eine „das Recht verletzende Willensäußerung [...], die von der Gemeinschaft nicht hingenommen werden kann" und folglich nach Missbilligung verlangt. ${ }^{10}$ Das Programm, nach dem sich die Wahl des Sanktionsinstrumentariums richtet, heißt im ersten Fall Prävention, im zweiten Fall Retribution. ${ }^{11}$ Die Präventionstheorien der Strafe halten den Rückgriff auf die Vergangenheit unter Legitimationsgesichtspunkten für unergiebig und verweisen stattdessen auf die $\mathrm{Zu}-$

2 Anselm v. FeUERbach, Revision der Grundsätze und Grundbegriffe des positiven peinlichen Rechts, Bd. I, 1799, Nachdruck 1966, S. 3.

3 Feuerbach (Anm. 2), S. 3.

4 FEUERBACH (Anm. 2), S. 5.

5 Dieser Begriff wird hier verwendet in Anlehnung an GÜNTHER SPENDEL, Grundfragen jeder Strafrechtsreform. Eine Studie zur Systematik des Strafrechts, in: Siegfried Hohenleitner u.a. (Hrsg.), Festschrift für Theodor Rittler zu seinem achtzigsten Geburtstag, 1957, S. 39, 40.

6 Zuletzt Ulfrid NeumanN, Institution, Zweck und Funktion staatlicher Strafe, in: Michael Pawlik/Rainer Zaczyk (Hrsg.), Festschrift für Günther Jakobs zum 70. Geburtstag, 2007, S. 435, 438 f. - Weitere Nachweise in: Michael Pawlik, Person, Subjekt, Bürger. Zur Legitimation von Strafe, 2004, S. 15 f.

7 FeUERbACH (Anm. 2), S. 4.

8 HeinZ-Gerd SCHMitZ, Zur Legitimität der Kriminalstrafe. Philosophische Erörterungen, 2001, S. 13.

9 SUSANNE WALTHER, Was soll „Strafe“? Grundzüge eines zeitgemäßen Sanktionensystems, ZStW 111 (1999), S. 123, 130.

10 Walther (Anm. 9), ZStW 111 (1999), S. 129.

11 Walther (Anm. 9), ZStW 111 (1999), S. 129 f. 
kunft. Diesen Auffassungen gemäß ist also zu strafen ne peccetur. Das Geschehene lässt sich nicht ungeschehen machen, aber mit Hilfe der Strafe lässt sich wenigstens das künftige gesellschaftliche Sicherheitsniveau günstig beeinflussen. Der Familie der Präventionslehren wende ich mich im folgenden zweiten Abschnitt zu. Die vergeltungstheoretisch (retributiv) orientierten Konzeptionen erblicken dagegen nicht nur den Real-, sondern auch den Rechtsgrund der Strafe in der Vergangenheit. Zu strafen sei quia peccatum est. Dieses Begründungsmodell erörtere ich im abschließenden dritten Teil meines Beitrags.

\section{Präventionstheoretische Strafbegründungen}

\section{Die Attraktivität des Präventionsdenkens}

Der staatstheoretische Ausgangspunkt der Präventionslehren ist von nachgerade unwidersprechbarer Überzeugungskraft: Der moderne Staat gründet seine Legitimation auf die Leistungen, die er seinen Bürgern erbringt. ${ }^{12}$ Die fundamentale staatliche Leistung ist - insoweit ist HOBBES unüberholt - die Leistung der Schutzgewährung. ${ }^{13}$ Dem Präventionsdenken zufolge rechtfertigt die Strafe sich unmittelbar dadurch, dass sie zur Erfüllung der genannten Schutzaufgabe beiträgt. ${ }^{14}$ Die Frage nach der genauen Ausgestaltung des Strafensystems stellt sich demnach als ein quasi technisches Optimierungsproblem dar, und das Ausmaß seiner Aufgabenerfüllung ist - jedenfalls im Prinzip - empirisch nachprüfbar. ${ }^{15}$ Eine insgesamt szientistisch geprägte und zukunftsorien-

12 Prägnant dazu jüngst WOLFGANG FACH, Leistung und Legitimation des modernen Staates, in: Diethelm Klesczewski u.a. (Hrsg.), Entstaatlichung und gesellschaftliche Selbstregulierung, 2008, S. $11 \mathrm{ff}$.

13 Vgl. Thomas HobBes, Leviathan, 5. Aufl. 1992, 21. Kap. (S. 171). - Auch das Bundesverfassungsgericht begreift das Strafrecht vor allem als Schutzrecht (vgl. etwa BVerfGE 21, S. 391, 403 f.; BVerfGE 27, S. 18, 29; BVerfGE 39, S. 1, 45, 187, 253; BVerfGE 51, S. 60, 74 f.; BVerfGE 80, S. 244, 255 f.; BVerfGE 88, S. 203, 257; BVerfGE 90, S. 145, 175, 184).

14 Alessandro Baratta, Jenseits der Strafe. Rechtsgüterschutz in der Risikogesellschaft, in: Fritjof Haft u.a. (Hrsg.), Strafgerechtigkeit. Festschrift für Arthur Kaufmann zum 70. Geburtstag, 1993, S. 393, 408 f.

15 Tatsächlich sind die (insbesondere general-)präventiven Wirkungen der Strafpraxis erfahrungswissenschaftlich nur schwer abzusichern (vgl. etwa MICHAEL BOCK, Ideen und Schimären im Strafrecht. Rechtssoziologische Anmerkungen zur Dogmatik der positiven Generalprävention, ZStW 103 [1991], S. 636, 654 ff.; ferner DENS., Prävention und Empirie. Über das Verhältnis von Strafzwecken und Erfahrungswissen, JuS 1994, S. 89, 96 ff.). In der Judikatur des Bundesverfassungsgerichts hat dies zu der paradoxen Konsequenz geführt, dass entgegen der Rede des Gerichts von der gesteigerten Bedeutung des Verhältnismäßigkeitsgrundsatzes für die Prüfung einer Strafvorschrift (etwa BVerfGE 25, S. 269, 286; BVerfGE 88, S. 203, 258; BVerfGE 90, S. 145, 172) die Anforderungen, die insofern tatsächlich an Strafgesetze gestellt werden, deut- 
tierte Kultur erkennt in den Präventionstheorien Geist von ihrem Geist und räumt ihnen deshalb typischerweise einen erheblichen Plausibilitätsvorschuss ein. ${ }^{16}$

Die klassischen Ausprägungen des Präventionsgedankens stellen die negative Generalprävention und die Spezialprävention dar. Die negative Generalprävention, welche auf die Abschreckung potentieller Täter setzt, macht sich die Vorstellung des kühl seinen Vorteil kalkulierenden homo oeconomicus zunutze, für den auch Kriminalität eine ökonomische Aktivität ist. Einem solchen klugen Nutzenmaximierer soll durch ein verlässlich funktionierendes Strafrechtssystem handgreiflich demonstriert werden, dass Delinquenz alles in allem eine unprofitable Lebensform ist (2.). Die Spezialprävention, die den Zweck der Strafe darin erblickt, den Täter von künftigen Taten abzuhalten, bedient sich demgegenüber einer quasi medizinischen Terminologie; sie fordert die „Behandlung“ und äußerstenfalls die „Unschädlichmachung“ der Straftäter (3.). Im Mittelpunkt der jüngeren straftheoretischen Diskussion steht indes ein dritter Spross aus der Familie der Präventionslehren: die Lehre von der positiven Generalprävention, auch Integrationsprävention genannt. Statt auf Abschreckung und Umerziehung setzt sie darauf, mittels der Strafe die Wertüberzeugungen der normtreuen Bürger zu bestätigen und zu stärken (4.).

\section{Die negative Generalprävention}

Die Lehre von der negativen Generalprävention mutet den Adressaten der Strafnormen keinen überflüssigen Idealismus zu. Sie betrachtet die Gesellschaftsmitglieder als Individuen, die zuallererst an ihrem eigenen Nutzen interessiert sind

lich geringer sind als jene Anforderungen, die an andere eingreifende Regelungen des Staates herangetragen werden (näher IVO APPEL, Verfassung und Strafe. Zu den verfassungsrechtlichen Grenzen staatlichen Strafens, 1998, S. 181 ff.).

16 Näher WOLFGANG BECK, Unrechtsbegründung und Vorfeldkriminalisierung. Zum Problem der Unrechtsbegründung im Bereich vorverlagerter Strafbarkeit, erörtert unter besonderer Berücksichtigung der Deliktstatbestände des politischen Strafrechts, 1992, S. 39; DETLEV FREHSEE, Schadenswiedergutmachung als Instrument strafrechtlicher Sozialkontrolle. Ein kriminalpolitischer Beitrag zur Suche nach alternativen Sanktionsformen, 1987, S. 58; WINFRIED HASSEMER, Strafziele im sozialwissenschaftlich orientierten Strafrecht, in: Winfried Hassemer/Klaus Lüderssen/Wolfgang Naucke, Fortschritte im Strafrecht durch die Sozialwissenschaften?, 1983, S. 39, 51 f.; DERS., Prävention im Strafrecht, JuS 1987, S. 257, 263; Peter HofFmanN, Zum Verhältnis der Strafzwecke Vergeltung und Generalprävention in ihrer Entwicklung und im heutigen Strafrecht, 1992, S. 114 ff.; WOLFGANG NAUCKE, Die Kriminalpolitik des Marburger Programms 1882, ZStW 94 (1982), S. 525, 533 f.; Ulfrid NeUmanN/Ulrich SCHROTH, Neuere Theorien von Kriminalität und Strafe, 1980, S. 10; CoRnelius PRITTWITZ, Strafrecht und Risiko. Untersuchungen zur Krise von Strafrecht und Kriminalpolitik in der Risikogesellschaft, 1993, S. 234. 
und diesen in rationaler Weise zu verfolgen wissen. ${ }^{17}$ Gerechtigkeit ohne eigenen Vorteil sei die größte Dummheit, folglich müsse alles Gerechte ein im Privatbereich Nützliches sein, so bringt LEIBNIZ ${ }^{18}$ diesen rechtsethischen Minimalismus auf den Begriff. ${ }^{19}$ Strafen müssen danach ,so eingerichtet werden,

17 Vgl. Felix Herzog, Prävention des Unrechts oder Manifestation des Rechts. Bausteine zur Überwindung des heteronom-präventiven Denkens in der Strafrechtstheorie der Moderne, 1987, S. 41 (kritisch); BERND SCHÜNEMANN, Zum Stellenwert der positiven Generalprävention in einer dualistischen Straftheorie, in: ders. u.a. (Hrsg.), Positive Generalprävention. Kritische Analysen im deutschenglischen Dialog, 1998, S. 109, 122 (affirmativ). - Der Ausgangspunkt beim homo calculans macht die Abschreckungslehre vor allem für die Vertreter der ökonomischen Theorie des Rechts attraktiv; grundlegend GARY S. BECKER, Der ökonomische Ansatz zur Erklärung menschlichen Verhaltens, 1993, S. 40 ff.; aus der deutschsprachigen Literatur ferner Michael AdAms/Steven Shavell, Zur Strafbarkeit des Versuchs, GA 1990, S. 337, 340 ff.; Horst EnTORF, Ökonomische Theorie der Kriminalität, in: Claus Ott/Hans-Bernd Schäfer (Hrsg.), Die Präventiventwicklung zivil- und strafrechtlicher Sanktionen, 1999, S. 1 ff.; Dieter SCHMidTCHEN, Wozu Strafrecht? Einige Anmerkungen aus ökonomischer Sicht, ebd., S. 49 ff.; DERS., Prävention und Menschenwürde. Kants Instrumentalisierungsverbot im Lichte der ökonomischen Theorie der Strafe, in: Dieter Dölling (Hrsg.), Jus humanum. Grundlagen des Rechts und Strafrecht. Festschrift für Ernst-Joachim Lampe zum 70. Geburtstag, 2003, S. 245, 266 ff.; VikTor VAnBerg, Verbrechen, Strafe und Abschreckung. Die Theorie der Generalprävention im Lichte der neueren sozialwissenschaftlichen Diskussion, 1982, S. $7 \mathrm{ff}$. - Weitere Anhänger dieser Strafkonzeption: Karsten Altenhain, Das Anschlußdelikt. Grund, Grenzen und Schutz des staatlichen Strafanspruchs und Verfallsrechts nach einer individualistischen Strafrechtsauffassung, 2002, S. 326 ff.; NORBERT HOERSTER, Zur Generalprävention als dem Zweck staatlichen Strafens, GA 1970, S. 272, 273 ff.; DERS., Zur Verteidigung von Schopenhauers Straftheorie der Generalprävention, Schopenhauer-Jahrbuch, Bd. 53 (1972), S. 101 ff.; EBERHARD SCHMIDHÄUSER, Strafrecht Allgemeiner Teil. Lehrbuch, 2. Aufl. 1975, 3/4; DERS., Über Strafe und Generalprävention, in: Rainer Zaczyk u.a. (Hrsg.), Festschrift für E. A. Wolff zum 70. Geburtstag, 1998, S. 443, 455.

18 Frühe Schriften zum Naturrecht, 2003, S. 329.

19 Die sozialwissenschaftliche Kritik an diesem spezifisch ökonomischen Denkmodell faßt Petra Wittig zusammen (Petra Wittig, Der rationale Verbrecher. Der ökonomische Ansatz zur Erklärung kriminellen Verhaltens, 1993, S. 126 ff.; DIES., Der ökonomische Ansatz zur Erklärung kriminellen Verhaltens, MschrKrim 1993, S. 328, 333 ff.). - Die neuere ökonomische Sozialtheorie hat auf diese Kritik mit der Einbeziehung verhaltenstheoretischer Positionen reagiert, was zu einer weitgehenden Subjektivierung des von ihr zugrunde gelegten Rationalitätskonzepts geführt hat (Überblick bei HANS-JOACHIM OTTO, Generalprävention und externe Verhaltenskontrolle. Wandel vom soziologischen zum ökonomischen Paradigma in der nordamerikanischen Kriminologie?, 1982, S. 101 ff.). Auch das Modell rationalen kriminellen Verhaltens wird in neueren Entwürfen mit soziologisch-kriminologischen Theorien kombiniert (HenNing CuRTI, Abschreckung durch Strafe. Eine ökonomische Analyse der Kriminalität, 1999, S. 56 ff.; ARNO LIPPERT, Verbrechen und Strafe. Ein Beitrag der ökonomischen Theorie zur Erklärung und Behandlung von Kriminalität, 1997, S. 293 ff.). 
daß sie in ihrer Härte schwerer wiegen als Gewinn und Genuß, den man aus der vom Gesetz verbotenen Tat ziehen könnte. “20 Dieses Strafverständnis lässt sich auf ein prima facie durchaus beachtliches Zweck-Mittel-Argument stützen.

Danach liegt eine Absenkung des Kriminalitätsniveaus innerhalb einer Gesellschaft ${ }^{21}$ im Interesse (praktisch) eines jeden Gesellschaftsmitglieds. ${ }^{22}$ Selbst derjenige, der seinen Lebensunterhalt durch Straftaten bestreitet, will typischerweise deren Früchte in Ruhe und Frieden genießen. Das Mittel der Abschreckung aber trägt nach der allgemeinen Lebenserfahrung nicht unerheblich zur Erreichung des Ziels der Kriminalitätsreduzierung bei. Das Wissen darum, dass Straftaten mit hinreichend großer Wahrscheinlichkeit bestraft werden, wirkt nämlich grosso modo auf tatgeneigte Individuen demotivierend; Straftaten, die ansonsten (d.h. im Falle der Abwesenheit eines funktionsfähigen Strafrechtssystems) begangen worden wären, werden auf diese Weise verhindert. Muss nun, wer den Zweck - die Kriminalitätsreduzierung - will, nicht auch das zu seiner Erreichung taugliche Mittel der (als Abschreckungsmittel konzipierten) Strafe akzeptieren?

Diese Schlussfolgerung ist jedoch vorschnell. In Bezug auf ein Gesellschaftsmitglied, das eine strafrechtlich sanktionierte Norm gebrochen hat, gilt sie nämlich nur mit einer bedeutsamen Einschränkung. Zwar entspricht es nach dem soeben Ausgeführten dem rationalen Interesse auch eines solchen Individuums, dass Strafen angedroht und mit hinreichender Regelmäßigkeit verhängt werden (denn ansonsten würden die Androhungen ja ihren Biss und damit ihre Glaubwürdigkeit einbüßen) ${ }^{23}$. Am günstigsten wäre es für ihn freilich, wenn lediglich die Normbrüche der übrigen Gesellschaftsmitglieder bestraft würden,

20 Samuel Pufendorf, Über die Pflicht des Menschens und des Bürgers nach dem Gesetz der Natur, 1994, II/11 \& 7 (S. 184).

21 Weil es realistischerweise nur um eine Absenkung, nicht aber um eine Ausrottung der Kriminalität gehen kann, stellt der Umstand, dass trotz der Existenz einer Strafrechtsordnung verbreitet delinquiert wird, keine Widerlegung der Lehre von der negativen Generalprävention dar. Deren Vertreter können nämlich auf die weitaus größere Zahl der trotz Tatanreiz und Tatmöglichkeit nicht begangenen Delikte verweisen (ALTENHAIN [Anm. 17], S. 329 f.; HOERSTER [Anm. 17], GA 1970, S. 274; DERS. [Anm. 17], Schopenhauer-Jahrbuch 1972, S. 105 f.; SCHMidHäUSER [Anm. 17], Strafrecht Allgemeiner Teil, 3/16; DERS., Vom Sinn der Strafe, 2. Aufl. 1971, S. 58, 76; DERS. [Anm. 17], Festschrift Wolff, S. 443, 446; BERND SCHÜNEMANN, Plädoyer für eine neue Theorie der Strafzumessung, in: Albin Eser/Karin Cornils (Hrsg.), Neuere Tendenzen der Kriminalpolitik, 1987, S. 222; VANBERG [Anm. 17], S. 26 f.).

22 Um eine interessentheoretische Fundierung der Präventionslehren bemühen sich MICHAEL BAURmanN, Strafe im Rechtsstaat, in: ders./Hartmut Kliemt (Hrsg.), Die moderne Gesellschaft im Rechtsstaat, 1990, S. 109, 115 ff.; NORBERT HOERSTER, Zur Begründung staatlichen Strafens, in: Werner Krawietz (Hrsg.), Theorie der Normen. Festgabe für Ota Weinberger zum 65. Geburtstag, 1984, S. 226, 233; VANBERG (Anm. 17), S. 11. Pathologische Randexistenzen wie der überzeugte Anarchist oder der Berufsrevolutionär bleiben insofern ausgeklammert.

23 So zuletzt Altenhain (Anm. 17), S. 327 f. 
während er selbst ungeschoren davonkäme. Die Verhängung der Strafe im Einzelfall, also jenen Akt, der tatsächlich weh tut und daher in hervorragendem MaBe legitimationsbedürftig ist, können wir dem Betroffenen gegenüber deshalb nicht mehr auf den Gesichtspunkt des klugen Eigeninteresses stützen. ${ }^{24}$

Dieser Befund konfrontiert die Vertreter der Lehre von der negativen Generalprävention mit einem Dilemma. Wollen sie an der begründungstheoretisch attraktiven, da voraussetzungsarmen Berufung auf den Topos des klugen Eigeninteresses festhalten, so müssen sie sich auf die Interessenlage sämtlicher (deliktsgeneigter) Gesellschaftsmitglieder mit Ausnahme des Verurteilten selbst beschränken. Diesen anderen Gesellschaftsmitgliedern wird mittels der Bestrafung des Täters vor Augen gefuihrt, dass Kriminalität sich nicht lohnt. Es wird also nicht mehr (auch) mit dem Verurteilten gesprochen, sondern nur noch vermittels seiner. Er wird - um eine Wendung WELCKERS aufzugreifen verwendet „,wie unbrauchbare Stoffe zur Vogelscheuche.“ ${ }^{25}$ Dies aber bedeutet, dass der Täter nur mehr ,in der rechtlichen Form, nicht aber nach dem Inhalt der Regelung“" als gleichberechtigtes Mitglied der Rechtsgemeinschaft behandelt wird. ${ }^{26}$ Auf diesem Wege lässt sich lediglich ein Akt der Exklusion

24 Auf den ersten Blick scheint man diesem Befund dadurch entgehen zu können, dass man den Gesellschaftsangehörigen die Fähigkeit zur Verfolgung komplexerer Zweckreihen zubilligt. Die Gesellschaftsmitglieder seien sich der destruktiven Konsequenzen einer allgemeinen Praxis des „Trittbrettfahrens“ bewusst. Deshalb entspreche es ihrem reflektierten Eigeninteresse, einer Bestrafungskonzeption zuzustimmen, die sicherstelle, dass das „Trittbrettfahren“ zu einer regelmäßig unattraktiven Verhaltensoption werde (in diesem Sinne zuletzt Dieter Schmidtchen, Prävention und Menschenwürde [Anm. 17], S. 245, 247 im Anschluss an BUCHANAN). Dieses Erklärungsmodell versagt aber jedenfalls dort, wo einem Gesellschaftsmitglied eine schwere Strafe droht, die seinen durch die Entmutigung einzelner ,Trittbrettfahrer“ bewirkten Sicherheitsgewinn übersteigt. Ferner ist die Annahme einer allgemeinen Praxis des „Trittbrettfahrens“ von vornherein unrealistisch. Die meisten Straftaten werden nicht aus klugem Eigeninteresse unterlassen, sondern deshalb, weil das betreffende Individuum in einer Weise sozialisiert ist, die ihm ein legales Verhalten als selbstverständlich erscheinen lässt. Aus diesem Grund schneidet sich ein zum „Trittbrettfahren“ entschlossener Täter keineswegs notwendig in das eigene Fleisch. Angesichts dieser Sachlage aber hat er unter Klugheitsgesichtspunkten keinen hinreichenden Anlass, seiner eigenen Bestrafung zuzustimmen.

25 Karl TheOdor Welcker, Die letzten Gründe von Recht, Staat und Strafe. Philosophisch und nach den Gesetzen der merkwürdigsten Völker rechtshistorisch entwickelt, 1813, Nachdruck 1964, S. 214. - Diese Konsequenz ergibt sich im übrigen auch daraus, dass die Strafe zur Setzung eines effektiven Gegenmotivs für den Täter selbst zu spät kommt: Er hat sich nicht abschrecken lassen. Unter Präventionsgesichtspunkten kann die Strafe deshalb allenfalls noch zur Abschreckung anderer nutzbar gemacht werden.

26 ERnst Amadeus WolfF, Das neue Verständnis von Generalprävention und seine Tauglichkeit für eine Antwort auf Kriminalität, ZStW 97 (1985), S. 786, 798. Grundlegend für die neuere Diskussion PETER BADURA, Generalprävention und Würde des Menschen, JZ 1964, S. 337, 343 f. 
begründen, aber keine Rechtsstrafe - denn zu dieser gehört in den Worten des Bundesverfassungsgerichts, dass der Täter ,nicht zum bloßen Objekt der Verbrechensbekämpfung gemacht werden“ darf ${ }^{27}$ und „nicht für vermutete kriminelle Neigungen Dritter büßen muß, sondern nach seiner Tat und seiner Schuld bestraft wird". 28

FEUERBACH hat dieses Problem weitaus schärfer erkannt als viele der späteren Abschreckungstheoretiker. Deshalb unterscheidet er strikt zwischen der Androhung und der Exekution des Strafübels. ${ }^{29}$ Den Geltungsanspruch der Präventionslogik beschränkt FEUERBACH auf den Bereich der Strafandrohung. ${ }^{30}$ Den Rechtsgrund für die Strafvollstreckung erblickt er dagegen in einer konkludenten Einwilligung des Delinquenten: Jeder, der das Recht habe, die Unterlassung bestimmter Handlungen zu fordern, habe auch das Recht, die Begehung dieser Handlungen unter eine ihm genehme Bedingung zu stellen; ${ }^{31}$ dies gelte auch für den Staat. ${ }^{32}$ Der Bürger müsse sich entweder der Bedingung unterwerfen oder die Handlung unterlassen. Begehe er gleichwohl die derart bedingte Tat, so berechtige er den Staat, die angedrohte Strafe zu vollziehen. ${ }^{33}$

Die Unhaltbarkeit dieser Konstruktion hat bereits FEUERBACHS Freund und Kontrahent GROLMAN aufgezeigt. In dem ,willkührlichen Faktum des Androhens" sei keineswegs ein Rechtsgrund für den auszuübenden Zwang enthalten. ${ }^{34}$ Allein der Umstand, dass der andere vorab um meine Entschlossenheit weiß, unter bestimmten Bedingungen Zwang anzuwenden, macht meine Reaktion, so sie denn erfolgt, noch nicht zu einer legitimen; entscheidend ist vielmehr die Legitimität der von mir aufgestellten Bedingungen. ${ }^{35}$ Diese Bedingungen leitet FEUERBACH wiederum aus den Vorgaben der Abschreckungslehre $a b .{ }^{36}$ Dies ist zwar konsequent; denn um ihrer Aufgabe, der Androhung zur Wirksamkeit zu verhelfen, ${ }^{37}$ in möglichst effektiver Weise zu entsprechen, müssen die Regeln, die über das Ob und das Wieviel der Strafe bestimmen, sich an die Wertungen des Abschreckungsdenkens anpassen. An-

27 BVerfGE 50, S. 205, 215.

28 BVerfGE 28, S. 386, 391.

29 FEUERBACH (Anm. 2), S. 52 f.

30 FeUerbach (Anm. 2), S. $49 \mathrm{ff}$.

31 FEUERBACH (Anm. 2), S. 53.

32 FEUERBACH (Anm. 2), S. 53.

33 FEUERBACH (Anm. 2), S. 54.

34 Karl Ludwig Wilhelm v. Grolman, Über die Begründung des Strafrechts und der Strafgesetzgebung, nebst einer Entwicklung der Lehre von dem Maasstabe der Strafen und der iuridischen Imputation, 1799, S. 10.

35 Grolman (Anm. 34), S. $12 \mathrm{ff}$.

36 Vgl. Anselm v. Feuerbach, Revision der Grundsätze und Grundbegriffe des positiven peinlichen Rechts, Bd. II, 1800, Nachdruck 1966, S. 39 f., 67.

37 Vgl. FeUerbach (Anm. 2), S. 52. 
drohung und Exekution von Strafe lassen sich nicht entkoppeln. ${ }^{38}$ Der Preis dafür ist allerdings hoch. So nimmt FEUERBACH an, dass ,,schlechte Erziehung “39 sowie ,natürliche Schwäche und Stumpfheit der höhern Geisteskräfte “40 die Strafbarkeit erhöhen - denn derartige Defekte unterstützten „nothwendig die Wirksamkeit und die Herrschaft der sinnlichen Begierden“, ${ }^{41}$ steigerten also die Gefährlichkeit des mit ihnen behafteten Menschen ${ }^{42}$ und bedürften daher zu ihrer Neutralisierung einer besonders nachdrücklichen Zwangsmaßnahme. ${ }^{43}$ Dies bedeutet freilich nichts Geringeres als eine Abkehr

38 Ebenso Heiner Bielefeldt, Strafrechtliche Gerechtigkeit als Anspruch an den endlichen Menschen. Zu Kants kritischer Begründung des Strafrechts, GA 1990, S. 108, 116; KARL-HeINZ GÖSSEL, Über die Bedeutung des Irrtums im Strafrecht, 1974, S. 247; DERS., Wesen und Begründung der strafrechtlichen Sanktionen, in: Otto Friedrich Freiherr von Gamm u.a. (Hrsg.), Strafrecht, Unternehmensrecht, Anwaltsrecht. Festschrift für Gerd Pfeiffer zum Abschied aus dem Amt als Präsident des Bundesgerichtshofes, 1988, S. 3, 21; HOERSTER (Anm. 17), GA 1970, S. 276; MiCHAEL KÖHLER, Strafrecht Allgemeiner Teil, 1997, S. 38; DERS., Über den Zusammenhang von Strafrechtsbegründung und Strafzumessung. Erörtert am Problem der Generalprävention, 1983, S. 28; DERS., Der Begriff der Strafe, 1986, S. 6, 13, 53 , 72 ff.; Elio MORSELli, Vergeltung. Eine tiefenpsychologische Kategorie der Strafe?, ARSP 87 (2001), S. 221, 227 f.; Spendel (Anm. 5), S. 50; Franz Streng, Kommentar zu „Kriterien für die Herstellung von Tatproportionalität”, in: Wolfgang Frisch u.a. (Hrsg.), Tatproportionalität. Normative und empirische Aspekte einer tatproportionalen Strafzumessung, 2003, S. 129. - Cum grano salis gilt der obige Einwand auch gegen den Vorschlag H. L. A. HARTS, die Institution der Strafe unter Rückgriff auf den Abschreckungsgedanken, konkrete Strafakte hingegen anhand eines retributiven Maßstabes zu rechtfertigen (Herbert Lionel AdOlPHUS HART, Recht und Moral. Drei Aufsätze, 1971, S. 66; zustimmend BJÖRN BURKHARDT, Zweckmoment im Schuldbegriff, GA 1976, S. 321, 341; PeTER Koller, Probleme der utilitaristischen Strafrechtfertigung, ZStW 91 [1979], S. 45, 46 f.; LothaR KuHLEN, Anmerkungen zur positiven Generalprävention, in: Bernd Schünemann u.a. [Hrsg.], Positive Generalprävention. Kritische Analysen im deutsch-englischen Dialog, 1998, S. 55, 59; VANBERG [Anm. 17], S. 8 f.; i. E. [ungeachtet seiner Betonung des in dieser Konzeption liegenden systematischen Bruchs] auch ThOMAS WeIGEND, Sind Sanktionen zu akzeptieren, die sich am Maß der Tatschuld orientieren?, in: Wolfgang Frisch u.a. [Hrsg.], Tatproportionalität. Normative und empirische Aspekte einer tatproportionalen Strafzumessung, 2003, S. 199, 200 f.). Ein konkreter Bestrafungsvorgang muss geduldet werden, weil und insofern die Strafe als solche eine legitime Institution ist. Die Legitimation einzelner Anwendungsakte einer Institution ist insofern eine gleichsam geborgte; sie ist abgeleitet von der Rechtfertigung, welche die Institution als Ganze trägt. Wenn Abschreckungsstrafen sich im Einzelfall - also dort, wo die Institution ihre realen Wirkungen zeitigt - nicht rechtfertigen lassen, dann beweist dieser Umstand, dass auch die Institution als Ganze anders verstanden werden muss.

39 FEUERBACH (Anm. 36), S. 417.

40 FEUERBACH (Anm. 36), S. 421.

41 Feuerbach (Anm. 36), S. 421.

42 Vgl. Feuerbach (Anm. 36), S. 335.

43 Feuerbach (Anm. 36), S. $333 \mathrm{ff}$. 
von dem ehrwürdigen Grundsatz, dass die Strafe ,,in einem gerechten Verhältnis zur Schwere der Tat und zum Verschulden des Täters stehen [muss] “. ${ }^{44}$ Es ist die Axiologik seines eigenen Systems, die sich hier gegen FEUERBACH wendet. Hat er eingangs der Revision noch mit Nachdruck den Unterschied zwischen Strafen und Sicherungsmaßnahmen betont, ${ }^{45}$ gelangt er an ihrem Ende bei einer Position an, in der die Strafe zu einem bloßen „Sicherungsmittel $^{\text {“46 }}$ gegen gefährliche Individuen degeneriert ist. Seine straftheoretische Konzeption spricht sich insofern selbst das Urteil. Dies zeigt: Zwar ist die abschreckende Funktion der Strafe eine ,unablösbare Begleiterscheinung“ jeder Strafverhängung ${ }^{47}$ und als solche auch durchaus erwünscht; als Legitimationsgrund der Strafe eignet sich der Abschreckungsgedanke dagegen nicht.

\section{Die Spezialprävention}

In der „Reformeuphorie“ der 1960er- und frühen 1970er-Jahre gewann eine Haltung die Oberhand, die mit FOUCAULT als "Scham vor dem Bestrafen“ umschrieben werden kann. ${ }^{48}$ Deshalb wurde der Gedanke der Spezialprävention häufig auf den Gesichtspunkt der Resozialisierung verkürzt. ${ }^{49}$ Die Spezialprävention gewann ihr oben erwähntes quasi-medizinisches Aussehen, ${ }^{50}$ es schien allein oder doch vordringlich darum zu gehen, dem einzelnen Delinquenten zu helfen, ihn von seinen sozialen Defekten zu heilen. Freilich: $\mathrm{Ob}$ der Einzelne eine Krankheit behandeln lässt, unterliegt grundsätzlich seiner freien Entscheidung. Eine Zwangsbehandlung lässt sich nur unter Berufung auf ein öffentliches Interesse anordnen. Dieses öffentliche Interesse liegt bei der Spezialprävention ebenso wie zuvor bei der negativen Generalprävention in der Verbesserung des gesellschaftlichen Sicherheitsniveaus; negativ gewendet: in der Verringerung der künftig zu erwartenden Kriminalitätsbelastung. Dieses identisch gebliebene Ziel soll aber diesmal nicht durch die Beeinflussung Dritter, sondern durch die Einwirkung auf den Delinquenten selbst erreicht werden.

In LISZTS Marburger Programm stehen deshalb neben der Resozialisierung (,Besserung der besserungsfähigen und besserungsbedürftigen Verbrecher“)

44 BVerfGE 50, S. 502, 214 f.

45 FeUerbach (Anm. 2), S. 19 ff.

46 FEUERBACH (Anm. 36), S. 332.

47 RICHARD SCHMIDT, Die Strafrechtsreform in ihrer staatsrechtlichen und politischen Bedeutung, 1912, S. 52.

48 Vgl. Michel Foucault, Überwachen und Strafen. Die Geburt des Gefängnisses, 1994, S. 17. - Näher WINFRIED HASSEMER, Freiheitliches Strafrecht, 2001, S. 91 ff.

49 Dazu Peter-AleXis Albrecht, Spezialprävention angesichts neuer Tätergruppen, ZStW 97 (1985), S. 831, 845.

50 Hassemer (Anm. 48), S. 94. - Über Vorläufer dieses Vorstellungskomplexes im kriminalpolitischen Denken des 18. und 19. Jahrhunderts unterrichtet GÜNTER STRATENWERTH, Strafrecht und Sozialtherapie, in: Arthur Kaufmann u.a. (Hrsg.), Festschrift für Paul Bockelmann zum 70. Geburtstag, 1979, S. 901, 908 f. 
gleichrangig zwei weitere Strategien der Kriminalitätsbekämpfung: die „Abschreckung der nicht besserungsbedürftigen Verbrecher" und vor allem die „Unschädlichmachung der nicht besserungsfähigen Verbrecher“ ${ }^{51}$ Es ist nicht „schwächliche Humanitätsduselei“, die bei LISZT dem Besserungsfähigen die Chance zur gesellschaftlichen Reintegration gewährt, sondern der Wunsch, durch „,eine kühle Anpassung der Verbrechensbekämpfungsmittel an die kriminelle Eigenart des Täters" einen möglichst effektiven Interessenschutz zu gewährleisten. ${ }^{52}$ Dementsprechend ist der Verbrecher für LISZT weniger ein Mitbürger als ein Störfaktor. ${ }^{53}$ Im Vordergrund seines Denkens steht deshalb weniger die Kritik an zweckloser Übelzufügung als vielmehr die Kritik an einer nicht zweckgerechten und daher ineffizienten Verbrechensbekämpfung. ${ }^{54}$ Dort, wo LISZT einen Friedensschluss zwischen der Gesellschaft und dem Verbrecher für nicht erreichbar hält, also im Falle der sogenannten „Unverbesserlichen“, legt er konsequenterweise eine große Härte an den Tag: „Gegen die Unverbesserlichen muss die Gesellschaft sich schützen; und da wir köpfen und hängen nicht wollen und deportieren nicht können, so bleibt nur die Einsperrung auf Lebenszeit (bzw. auf unbestimmte Zeit)“".55

Diese „häßliche Seite der Spezialprävention“56 erinnert daran, dass die Resozialisierung innerhalb der Lehre von der Spezialprävention keinen Selbstzweck, sondern lediglich den Reflex einer gesellschaftspolitisch nützlichen Strategie darstellt. Dies wirkt einem unangebrachten rhetorischen Überschwang entgegen. Über die Tauglichkeit des Spezialpräventionsgedankens als Grundlage einer Straftheorie ist damit noch nicht entschieden. Conditio sine qua non ist insofern, dass die Art und Weise des Umgangs mit abweichendem Verhalten, die sich dem spezialpräventiven Denken empfiehlt, noch die charakteristischen Züge der Strafe aufweist. Sollte dies nicht der Fall sein, so besäße die Lehre von der Spezialprävention keinen Anspruch auf den Titel einer Straftheorie. ${ }^{57}$ Sie würde dann nämlich nicht die Legitimität der tatsächlich praktizierten

51 FranZ VON LisZt, Der Zweckgedanke im Strafrecht, ZStW 3 (1883), S. 1, 36.

52 Eberhard Schmidt, Vergeltung, Sühne und Spezialprävention, ZStW 67 (1955), S. 177, 181. - Klarstellend auch WOLfGANG FRISCH, Das Marburger Programm und die Maßregeln der Besserung und Sicherung, ZStW 94 (1982), S. 565, 576 sowie Michael Kubink, Strafen und ihre Alternativen im zeitlichen Wandel, 2002, S. 101.

53 GÜNTHER JAKOBS, Strafrecht als wissenschaftliche Disziplin, in: Christoph Engel/ Wolfgang Schön (Hrsg.), Das Proprium der Rechtswissenschaft, 2007, S. 103, 120.

54 Thomas Vormbaum, „Politisches” Strafrecht, ZStW 107 (1995), S. 734, 736.

55 LisZT (Anm. 51), S. 38 (Hervorhebungen im Original).

56 So Michael Walter, Ambulante Behandlung im Kriminalrecht, in: Rolf Dietrich Herzberg (Hrsg.), Festschrift für Dietrich Oehler zum 70. Geburtstag, 1985, S. 693, 695.

57 Eben dies ist die Auffassung MERKELS, der der Spezialpräventionslehre eine „mißbräuchliche Anwendung“ des Wortes Strafe vorwirft (AdOLF MERKEL, Die Lehre von Verbrechen und Strafe, 1912, S. 214). 
Institution „Strafe“ begründen, sondern einen „Wortschmuggel“58 betreiben, d.h. unter dem Anschein terminologischer Kontinuität einer Ersetzung der Strafe durch ein andersartiges Rechtsinstitut (,soziales Interventionsrecht ${ }^{459}$ ) das Wort reden.

Wie eingangs ausgeführt, gehört zu den begriffsbildenden Merkmalen der Strafe deren reaktiv-missbilligender Charakter: Die Strafe reagiert auf eine unrechtliche Handlung, deren Begehung sie dem Bestraften tadelnd vorhält. Sie ist also, um diesen Sachverhalt in strafrechtsdogmatisch vertraute und im heutigen deutschen Rechtssystem darüber hinaus verfassungsrechtlich abgesicherte Termini zu kleiden, an das Tat- sowie das Schuldprinzip gebunden. ${ }^{60}$ Ein Rechtsinstitut zum Umgang mit abweichendem Verhalten, dessen Zulässigkeit nicht von der Beachtung dieser beiden Grundsätze abhinge, ließe sich nicht mehr als Strafe in dem uns geläufigen Sinn bezeichnen. Nun ist bereits häufig darauf hingewiesen worden, dass eine Spezialprävention à la LISZT, konsequent durchgeführt, zur Preisgabe sowohl des Schuld- als auch des Tatprinzips tendiert. Die künftige Gefährlichkeit des Delinquenten ist unabhängig von dem Gewicht der sozialen Störung, die sich in der vergangenen Tat manifestierte, ${ }^{61}$ insbesondere auch davon, ob diese Tat schuldhaft begangen worden ist oder nicht. ${ }^{62} \mathrm{Im}$ Hinblick auf einen Täter, der ein schweres Delikt begangen hat, von dem aber keine Wiederholungsgefahr droht, bestünde kein spezialpräventives Behandlungsinteresse, ein „unverbesserlicher“ Kleinkrimineller müsste hingegen mit dauerhafter Unschädlichmachung rechnen. ${ }^{63} \mathrm{Um}$ Kriminalität

58 JOHANNeS NAGLER, Die Strafe. Eine juristisch-kriminalistische Untersuchung, 1918, S. 6.

59 Vgl. etwa Klaus Lüderssen, Abschaffen des Strafens?, 1995, S. 172.

60 Zum Verfassungsrang des Schuldprinzips vgl. BVerfGE 6, S. 389, 439; BVerfGE 9, S. 167, 169; BVerfGE 20, S. 323, 331; BVerfGE 25, S. 269, 286; BVerfGE 28, S. 386, 391; BVerfGE 50, S. 205, 214 f.; BVerfGE 86, S. 288, 313; BVerfGE 91, S. 1, 17; BVerfGE 95, S. 96, 140; BVerfGE 109, S. 133, 173 ff.

61 GÜNThER JAKOBS, Strafrecht Allgemeiner Teil. Die Grundlagen und die Zurechnungslehre, 2. Aufl. 1991, 1/43 ff. Ebenso FreHSEe (Anm. 16), S. 72; HeIko HartMUT LESCH, Zur Einführung in das Strafrecht: Über den Sinn und Zweck staatlichen Strafens, JA 1994, S. 590, 593; Reinhart MAUrach/HeinZ Zipf, Strafrecht Allgemeiner Teil, Teilband 1. Grundlehren des Strafrechts und Aufbau der Straftat, 8. Aufl. 1992, \5, Rn. 5.

62 Dies ist bereits von den Zeitgenossen LisZTs erkannt und hervorgehoben worden; vgl. nur ADOLF MERKEL, Gesammelte Abhandlungen aus dem Gebiet der allgemeinen Rechtslehre und des Strafrechts, Zweiter Teil, 1899, S. 706 f. - Aus der neueren Literatur: ARmin KaufmanN, Strafrechtsdogmatik zwischen Sein und Wert. Gesammelte Aufsätze und Vorträge, 1982, S. 271; LeSCH (Anm. 61), S. 594.

63 Jakobs (Anm. 61), 1/45; HANS-HeinRiCH JeSCHECK/ThOMAS Weigend, Lehrbuch des Strafrechts. Allgemeiner Teil, 5. Aufl. 1996, \ 8 IV 5 (S. 75); KÖHLER (Anm. 38), Strafrecht Allgemeiner Teil, S. 41; THEODOR LENCKNER, Strafe, Schuld und Schuldfähigkeit, in: Hans Göppinger/Hermann Witter (Hrsg.), Handbuch der forensischen Psychiatrie, Bd. I, 1972, S. 3, 16; LESCH (Anm. 61), S. 593 f.; MANFRED 
besonders nachhaltig zu verhüten, empfiehlt es sich zudem, erst gar nicht auf das Geschehen einer Straftat zu warten, sondern gefährliche Individuen bereits im Vorfeld den geeigneten Maßnahmen zu unterziehen. ${ }^{64}$

LISZT hat diese Gefahren durchaus gesehen, tat sich mit der Zurückweisung der betreffenden Einwände aber sichtlich schwer. ${ }^{65}$ Ausdrücklich konzediert er, „daß es vielleicht in der Konsequenz unserer Anschauung wäre, nur auf die Gesinnung Rücksicht zu nehmen, und nicht erst die Tat abzuwarten; wie ja auch der Hausarzt nicht wartet, bis ein Leiden zum Ausbruche kommt, sondern demselben vorzubeugen trachtet. " ${ }^{66}$ Dass diese Folgerung, obschon sie keineswegs absurd sei, ${ }^{67}$ dennoch nicht gezogen werden solle, begründet LISZT mit dem Interesse des einzelnen Bürgers an der Wahrung seiner Freiheit; dieses Interesse verlange nach einer eindeutigen Begrenzung der staatlichen Strafgewalt. ${ }^{68}$ LISZT selbst konkretisiert diesen Hinweis nicht näher. Im Ergebnis trifft es aber zu, dass ein strikt spezialpräventiv konzipiertes Strafrecht die Handlungsfreiheit des einzelnen Bürgers in einer kaum mehr kalkulierbaren Weise bedrohen würde. ${ }^{69}$ So müsste beispielsweise die Entscheidung darüber, ob jemand so gefährlich sei, dass er einer vorbeugenden Behandlung bedürfe, entweder auf einer stark lückenhaften Tatsachengrundlage ergehen (und wäre entsprechend schlecht prognostizierbar und fehleranfällig) ${ }^{70}$ oder aber sie würde eine äußerst intensive Überwachung der Bürger erfordern (und deren Freiheit aus diesem Grunde unterminieren). Für Individuen, die neben dem Bedürfnis nach Sicherung durch das Recht auch das Bedürfnis nach Sicherheit vor dem Recht haben, ist deshalb ein spezialpräventiv ausgerichtetes Strafrecht von vornherein allenfalls dann akzeptabel, wenn dieses Strafrecht als auslösendes Moment der staatlichen Reaktion eine schuldhafte Tat verlangt. Dies läuft frei-

MAIWALD, Moderne Entwicklungen der Auffassung vom Zweck der Strafe, in: Ulrich Immenga (Hrsg.), Rechtswissenschaft und Rechtsentwicklung, 1980, S. 291, 295; Claus Roxin, Strafrecht Allgemeiner Teil, Bd. I. Grundlagen. Der Aufbau der Verbrechenslehre, 4. Aufl. 2006, \3, Rn. 16, 19; SCHMIDHÄUSER (Anm. 17), Strafrecht Allgemeiner Teil, 3/17; GÜNTER Stratenwerth/Lothar Kuhlen, Strafrecht Allgemeiner Teil I. Die Straftat, 5. Aufl. 2004, S 1, Rn. 19.

64 Aus dem älteren Schrifttum: KARL VON BIRKMEYER, Die Strafgesetzgebung der Gegenwart in rechtsvergleichender Darstellung, ZStW 16 (1896), S. 95, 117; MERKEL (Anm. 62), S. 706 f.; Richard SCHMIDT, Die Aufgaben der Strafrechtspflege, 1895, S. 139. - Neuere Stimmen: JÜRgen BAUMANN/Ulrich Weber/WOlfGANG MitsCH, Strafrecht Allgemeiner Teil, 10. Aufl. 1995, \3, Rn. 46; JeSCHECK/ Weigend (Anm. 63), \8 IV 5 (S. 75); MAURACH/ZIPF (Anm. 61), \5, Rn. 5; RoXIN (Anm. 63), \3, Rn. 16; JAKobS (Anm. 53), S. 120; LesCH (Anm. 61), S. 594.

65 So auch die Einschätzung von Frisch (Anm. 52), S. 584.

66 FranZ VON LisZT, Strafrechtliche Aufsätze und Vorträge, Bd. II, 1905, S. 16.

67 Vgl. LiszT (Anm. 66), S. 59.

68 LiszT (Anm. 66), S. 60, 80 f.

69 Dies betonen bereits BiRKMEYer (Anm. 64), S. 95, 116 ff. und SCHMidT (Anm. 64), S. 139 ff. - Ebenso FrisCH (Anm. 52), S. 585 f.

70 Darauf stellt Walter (Anm. 56), S. 699 hauptsächlich ab. 
lich auf einen unterschiedlichen Aufbau des Strafvoraussetzungs- und des Strafbemessungsrechts hinaus: dort Tatprinzip, hier Täterorientierung. ${ }^{71}$ Die Axiologik des einen Komplexes diskreditiert die des anderen. Eine überzeugende Straftheorie lässt sich aus zwei solchermaßen widerstreitenden Hälften nicht zusammenfügen.

\section{Die positive Generalprävention}

Die negative Generalprävention setzt darauf, die Gesellschaftsmitglieder in ihrer Eigenschaft als rationale Vertreter ihrer je individuellen Interessen von der Vorzugswürdigkeit einer Selbstdisziplinierung überzeugen zu können. Dieses Begründungsmodell erfordert nicht, dass die Gesellschaftsmitglieder in ihrer Rolle als Normunterworfene die Institute des Rechts in deren intrinsischem Sollenscharakter anerkennen. ${ }^{72}$ Es genügt, dass sie dem Blick auf die Normen und deren Anwendung die Information entnehmen, ein Rechtsbruch werde sich voraussichtlich nicht lohnen. Eine solche, rein instrumentelle Beziehung der Bürger zu ihrer Rechtsordnung ist indessen höchst instabil, denn die Erfüllung einer jeden Rechtspflicht steht hier unter dem Vorbehalt ihrer individuellen Nützlichkeit für den Pflichtigen. ${ }^{73}$ Vorzugswürdig ist es, wenn die Bürger statt aufgrund von jeweils punktuellen Entscheidungen aufgrund von habituell gewordenen Dispositionen handeln. ${ }^{74}$ Deshalb wird in Rechtssoziologie, ${ }^{75}$ Kri-

71 Bekanntlich verfuhr LISZT in eben dieser Weise. Die Voraussetzungen der Strafbarkeit wollte er nach liberal-rechtsstaatlichen Grundsätzen bestimmen, ganz so, wie es die klassische Schule vertrat. Die Sanktion sollte hernach aber allein nach den sozialen Bedürfnissen bemessen werden (exemplarisch LisZT [Anm. 66], S. 71). Nach der Binnenlogik von LISZTS System bleiben die rechtsstaatlichen Einhegungen des Strafrechts jedoch stets in der Defensive. Sie sind, wie Ulfrid NeumanN, Vom normativen zum funktionalen Strafrechtsverständnis, in: Heike Jung u.a. (Hrsg.), Perspektiven der Strafrechtsentwicklung, 1996, S. 57, 64 hervorhebt, „dem therapeutischen Strafrecht äußerlich und aus seiner Sicht bedauerliche Hindernisse auf dem Weg zur größtmöglichen Effizienz.“ Deshalb stehen sie unter dem beständigen „Druck der nach rechtlichen Freiräumen verlangenden Kriminalpolitik“ (UlFRID NEUMANN a.a.O., S. 64; ebenso Peter Kaenel, Die kriminalpolitische Konzeption von Carl Stooss im Rahmen der geschichtlichen Entwicklung von Kriminalpolitik und Straftheorien, 1981, S. 73 f.; Kubink [Anm. 52], S. 295; WolfGang NAUCKe, Die Kriminalpolitik des Marburger Programms 1882, ZStW 94 [1982], S. 541, 544 ff.; Claus RoxiN, Franz von Liszt und die kriminalpolitische Konzeption des Alternativentwurfs, ZStW 81 [1969], S. 613, 640 f.; VORMBAUM [Anm. 54], S. 736).

72 JeNS CHRISTIAN MÜLLER-TUCKFELD, Integrationsprävention. Studien zu einer Theorie der gesellschaflichen Funktion des Strafrechts, 1998, S. 92.

73 Michael BaUrmanN, Vorüberlegungen zu einer empirischen Theorie der positiven Generalprävention, GA 1994, S. 368, 371.

74 BAURMANN (Anm. 73), S. 374.

75 Vgl. Michael Baurmann, Zehn Thesen zum Verhältnis von Normanerkennung, Legitimität und Legalität, in: Klaus Lüderssen (Hrsg.), Aufgeklärte Kriminalpolitik oder 
minalpolitik ${ }^{76}$ und Sozialphilosophie die Bedeutung nicht-instrumenteller Faktoren für das Recht betont. Dessen soziale Geltung hänge zu einem guten Teil $\mathrm{ab}$,von der Anerkennung seiner (ethisch-sittlichen) Verbindlichkeit, die ihrerseits nicht erzwingbar ist. ${ }^{\text {" } 77}$

Die Lehre von der positiven Generalprävention hat diesen Gedanken für den Bereich des Strafrechts fruchtbar gemacht. ${ }^{78}$ Danach soll die Strafe - mit

Kampf gegen das Böse?, Bd. 1, 1998, S. 409, 411 f.; DENS., Recht und intrinsische Motivation, in: Cornelius Prittwitz u.a. (Hrsg.), Festschrift für Klaus Lüderssen zum 70. Geburtstag, 2002, S. 17, 29.

76 Vgl. HeinZ ZIPF, Kriminalpolitik. Ein Lehrbuch, 2. Aufl. 1980, S. 40.

77 ERnST-WolfGANG BÖCKENFÖRdE, Staat, Nation, Europa, Studien zur Staatslehre, Verfassungstheorie und Rechtsphilosophie, 2002, S. $251 \mathrm{f}$.

78 Aus der älteren Literatur: Hellmuth MAYer, Das Strafrecht des deutschen Volkes, 1936, S. 26, 30 ff., 195 f.; Peter Noll, Schuld und Prävention unter dem Gesichtspunkt der Rationalisierung des Strafrechts, in: Friedrich Geerds/Wolfgang Naucke (Hrsg.), Beiträge zur gesamten Strafrechtswissenschaft. Festschrift für Hellmuth Mayer zum 70. Geburtstag, 1966, S. 219, 223 ff.; Gerald GrÜNWALD, Das Rechtsfolgensystem des Alternativ-Entwurfs, ZStW 80 (1968), S. 89, 92 ff. - Vertreter dieser Position innerhalb der neueren Diskussion: HANS ACHENBACH, Individuelle Zurechnung, Verantwortlichkeit, Schuld, in: Bernd Schünemann (Hrsg.), Grundfragen des modernen Strafrechtssystems, 1984, S. 135, 142 ff.; UDO EBERT, Das Vergeltungsprinzip im Strafrecht, in: Hans-Henrik Krummacher (Hrsg.), Geisteswissenschaften wozu? Beispiele ihrer Gegenstände und ihrer Fragen, 1988, S. 35, 46 f., 52 f.; GEORG FrEUND, in: Wolfgang Joecks/Klaus Miebach (Hrsg.), Münchener Kommentar zum Strafgesetzbuch, Bd. 1, 2003, Vor $\int S 13$ ff., Rn. 68, 91; DERS., Erfolgsdelikt und Unterlassen. $\mathrm{Zu}$ den Legitimationsbedingungen von Schuldspruch und Strafe, 1992, S. 105 ff.; DERS., Zur Legitimationsfunktion des Zweckgedankens im gesamten Strafrechtssystem, in: Jürgen Wolter/Georg Freund (Hrsg.), Straftat, Strafzumessung und Strafprozeß im gesamten Strafrechtssystem, 1996, S. 43, 48 f.; BERNHARD HAFFKE, Tiefenpsychologie und Generalprävention. Eine strafrechtstheoretische Untersuchung, 1976, S. 62 ff., 79 ff., 162 ff.; WINFRIED HASSEMER, Einführung in die Grundlagen des Strafrechts, 2. Aufl. 1990, S. 324 ff.; DERS., Strafziele (Anm. 16), S. 39, 64 f.; DERS. (Anm. 16), JuS 1987, S. 264 f.; DERS., Variationen der positiven Generalprävention, in: Bernd Schünemann u.a. (Hrsg.), Positive Generalprävention. Kritische Analysen im deutsch-englischen Dialog, 1998, S. 29, 34 ff.; DERS. (Anm. 48), S. 109 ff.; DERS., Darf der strafende Staat Verurteilte bessern wollen? Resozialisierung im Rahmen positiver Generalprävention, in: Cornelius Prittwitz u.a. (Hrsg.), Festschrift für Klaus Lüderssen zum 70. Geburtstag, 2002, S. 221, 238 f.; JAKOBS (Anm. 61), 1/14 ff.; DERS., Schuld und Prävention, 1976, S. 31 ff.; Justus KRÜMPELMANN, Dogmatische und empirische Probleme des sozialen Schuldbegriffs, GA 1983, S. 337, 343 f.; Maiwald (Anm. 63), S. 303; Santiago Mir Puig, Die begründende und die begrenzende Funktion der positiven Generalprävention, ZStW 102 (1990), S. 914, 922 f.; Reinhard Moos, Positive Generalprävention und Vergeltung, in: Walter Melnizky/Otto F. Müller (Hrsg.), Strafrecht, Strafprozeßrecht und Kriminologie. Festschrift für Franz Pallin zum 80. Geburtstag, 1989, S. 283, 300 ff.; BERND MÜSSIG, Schutz abstrakter Rechtsgüter und abstrakter Rechtsgüterschutz, 1994, S. 140 ff.; ОтTO (Anm. 19), S. 264 ff., 276 ff.; Jan Philipp Reemtsma, Das Recht des Opfers auf die Bestrafung des Täters, 1999, S. 20 ff.; Albert-Peter Rethmann, Der 
RICHARD SCHMIDT gesprochen - als „Zucht zum Guten“79 „,das Rechts- und Staatsgefühl derer stärken, die bei dem Konflikt zwischen Verbrechen und Staat auf seiten des Staats stehen, die das begangene und strafwürdige Unrecht mißbilligen. “80 Strafe ist danach „,nur ein Verstärkungsmittel. Im Vordergrund steht die Überzeugungskraft der Norm selbst. " 81 Dies setzt freilich voraus, dass „die Machtäußerung“ des Staates ,in Übereinstimmung mit den Anschauungen der Bürger über die Handlung und deren zu erwartende Folgen" steht. ${ }^{82}$ Eine Strafe muss sozial als gerecht anerkannt sein, um eine der gesellschaftlichen Integration förderliche Wirkung entfalten zu können. ${ }^{83}$ Ansonsten träte -

umstrittene Nutzen der Strafe, Rechtstheorie 31 (2000), S. 114, 133 ff.; BERND SChÜNEMANN, Die Funktion des Schuldprinzips im Präventionsstrafrecht, in: ders. (Hrsg.), Grundfragen des modernen Strafrechtssystems, 1984, S. 153, 187; DERS., Die deutschsprachige Strafrechtswissenschaft nach der Strafrechtsreform im Spiegel des Leipziger Kommentars und des Wiener Kommentars, GA 1986, S. 294, 349 ff.; FranZ Streng, Schuld, Vergeltung, Generalprävention. Eine tiefenpsychologische Rekonstruktion strafrechtlicher Zentralbegriffe, ZStW 92 (1980), S. 637, 648 ff.; DERS., Schuld ohne Freiheit? Der funktionale Schuldbegriff auf dem Prüfstand, ZStW 101 (1989), S. 273, 287 ff.; DERS. (Anm. 38), S. 131; KRISTIN TOMFORDE, Die Zulässigkeit einer Unterschreitung der schuldangemessenen Strafe aus präventiven Gesichtspunkten, 1999, S. 90; BAUMANN/WeBER/Mitsch (Anm. 64), \3, Rn. 30 ff., 65.

79 SCHMidT (Anm. 64), S. 25.

80 SCHMidT (Anm. 64), S. 52.

81 KRÜMPELMANN (Anm. 78), S. 343.

82 Schmidt (Anm. 64), S. 62; vgl. auch Merkel (Anm. 62), S. 721; DenS. (Anm. 57), S. $231 \mathrm{f}$.

83 Bedeutsam für die Nachkriegsdiskussion: SCHMIDT (Anm. 52), S. 187; FRIEDRICH NowAKOwski, Freiheit, Schuld, Vergeltung, in: Siegfried Hohenleitner u.a. (Hrsg.), Festschrift für Theodor Rittler zu seinem 80. Geburtstag, 1957, S. 55, 65 f., 85 ff.; WilHelm Gallas, Gründe und Grenzen der Strafbarkeit, in: Heidelberger Jahrbücher, Bd. IX, 1965, S. 1, 4; Peter Noll, Die ethische Begründung der Strafe, 1962, S. 22; DERS. (Anm. 78), S. 219, 223; KARL LACKNER, Der Alternativentwurf und die praktische Strafrechtspflege, JZ 1967, S. 513, 515 f.; HANS-HEINRICH JESCHECK, Die kriminalpolitische Konzeption des Alternativ-Entwurfs eines Strafgesetzbuchs (Allgemeiner Teil), ZStW 80 (1968), S. 54, 59; Hartmuth HorstKotTe, Die Vorschriften des Ersten Gesetzes zur Reform des Strafrechts über die Strafbemessung. (SS 13-16, 60 StGB), JZ 1970, S. 122, 125. - Gegenwärtige Vertreter: ACHENBACH (Anm. 78), S. 135, 143 ff.; BaUrmann (Anm. 73), S. 379 ff.; Paul Bockelmann, Zur Kritik der Strafrechtskritik, in: Günter Warda u.a. (Hrsg.), Festschrift für Richard Lange zum 70. Geburtstag, 1976, S. 1, 5 f.; DiETER DÖLling, Generalprävention durch Strafrecht: Realität oder Illusion, ZStW 102 (1990), S. 1, 15 f.; MK-FrEUND (Anm. 78), Vor $\iint 13$ ff., Rn. 69, 87; DERS. (Anm. 78), Erfolgsdelikt, S. 107 f.; KAI HART-HÖNIG, Gerechte und zweckmäßige Strafzumessung. Zugleich ein Beitrag zur Theorie positiver Generalprävention, 1992, S. 98 ff.; HeINRICH HENKEL, Die ,richtige“ Strafe. Gedanken zur richterlichen Strafzumessung, 1969, S. 40; JESCHECK/WEIGEND (Anm. 63), \ 8 II 4 (S. 69), IV 5 (S. 75), V 1 (S. 76); Angela Kalous, Positive Generalprävention durch Vergeltung, 2000, S. 249 ff.; WALTER KARGL, Friedenssicherung 
ebenso wie bei der negativen Generalprävention, jetzt aber nicht mehr beschränkt auf deliktsgeneigte Bürger, sondern als allgemeine Haltung - Furcht an die Stelle des einsichtsvollen Lernens, die Herausbildung von Rechtsvertrauen würde sich auf eine rein äußerlich bleibende Anpassungsleistung reduzieren, und das allgemeine Rechtsbewusstsein würde nicht beruhigt, sondern einer dauernden Irritation ausgesetzt werden.

Solange die Lehre von der positiven Generalprävention sich mit dem Anspruch begnügt, ein allgemeines rechtssoziologisches Theorem für das Verständnis des Strafrechts nutzbar zu machen, solange sie sich also lediglich als eine Strafrechtstheorie versteht, welche von einem systemexternen Standpunkt aus die Funktion des Strafrechts und seiner Sanktionen in der Gesellschaft erklärt ${ }^{84}$ - solange ist gegen diese Konzeption nichts Grundsätzliches einzuwen-

durch Strafrecht. Teleologische Strafrechtfertigung am Beispiel der Tötungsdelikte, ARSP 82 (1996), S. 485, 507; URS KINDHÄUSER, Personalität, Schuld und Vergeltung. Zur rechtsethischen Legitimation und Begrenzung der Kriminalstrafe, GA 1989, S. 493, 503 ff.; GEORG KÜPPER, Schopenhauers Straftheorie und die aktuelle Strafzweckdiskussion, Schopenhauer-Jahrbuch, Bd. 71 (1990), S. 207, 211; KARLLUDWIG KUNZ, Prävention und gerechte Zurechnung. Überlegungen zur normativen Kontrolle utilitaristischer Strafbegründung, ZStW 98 (1986), S. 823, 831 f.; LENCKNER (Anm. 63), S. 23 f.; MANFRED MAIWALD, Die Verteidigung der Rechtsordnung. Analyse eines Begriffs, GA 1983, S. 49, 54 f.; DERS. (Anm. 63), S. 291, 303; Olaf MieHe, Das Ende des Strafrechts, in: Peter Christian MüllerGraff/Herbert Roth (Hrsg.), Recht und Rechtswissenschaft. Signaturen und Herausforderungen zum Jahrtausendbeginn, 2000, S. 249, 252; Moos (Anm. 78), S. 283, 305; Morselli (Anm. 38), S. 230; HeINZ MÜlleR-Dietz, Integrationsprävention und Strafrecht. Zum positiven Aspekt der Generalprävention, in: Theo Vogler u.a. (Hrsg.), Festschrift für Hans-Heinrich Jescheck zum 70. Geburtstag, 2. Halbbd., 1985, S. 813, 824 ff.; Ulfrid NeUmAnN, Zurechnung und „Vorverschulden“. Vorstudien zu einem dialogischen Modell strafrechtlicher Zurechnung, 1985, S. 270 ff.; DERS., Neue Entwicklungen im Bereich der Argumentationsmuster zur Begründung oder zum Ausschluß strafrechtlicher Verantwortlichkeit, ZStW 99 (1987), S. 567, 589 ff.; DERS. (Anm. 71), S. 57, 67 f.; DERS., Kritik und Rechtfertigung des Strafrechts, 2005, S. $148 \mathrm{ff}$; DERS., Ontologische, funktionale und sozialethische Deutung des strafrechtlichen Schuldprinzips, in: Klaus Lüderssen (Hrsg.), Aufgeklärte Kriminalpolitik oder Kampf gegen das Böse?, Bd. 1, 1998, S. 391, 400 ff.; ОтTO (Anm. 19), S. 270 f., 276, 284 f.; Claus Roxin, Praktikabilität und Legitimität der „Spielraumtheorie“, in: Guido Britz u.a. (Hrsg.), Grundfragen staatlichen Strafens. Festschrift für Heinz Müller-Dietz zum 70. Geburtstag, 2001, S. 701, 709; SCHMIDHÄUSER (Anm. 17), Strafrecht Allgemeiner Teil, 3/19; Walter Stree, in: Adolf Schönke/Horst Schröder, Strafgesetzbuch. Kommentar, 27. Aufl. 2006, Vorbem. \$S 38 ff., Rn. 3; Streng (Anm. 78), ZStW 92 (1980), S. 663; Ders., (Anm. 78), ZStW 101 (1989), S. 292 ff., 332; DERS., Strafrechtliche Sanktionen. Grundlagen und Anwendung, 1991, S. 12; Tomforde (Anm. 78), S. 88; BAumanN/Weber/MitsCH (Anm. 64), $\$ 3$, Rn. 65.

84 Exemplarisch für dieses Verständnis der positiven Generalprävention ist JAKOBS’ Funktionalismus (zusammenfassend GÜNTHER JAKOBS, Das Strafrecht zwischen Funktionalismus und ,alteuropäischem” Prinzipiendenken, ZStW 107 [1995], S. 843 ff.; zur 
den. Weitaus problematischer wird die Sachlage, sobald die Lehre von der positiven Generalprävention als eine genuine Straftheorie ausgegeben wird, sobald ihr also der Anspruch zugeschrieben wird, eine Antwort auf die Frage zu bieten, weshalb es überhaupt Strafe geben dürfe.

Die soeben erwähnte rechtssoziologisch-externe Perspektive ist notwendig mit einer distanzierten Haltung des betreffenden Beobachters gegenüber den von ihm festgestellten sozialen Wertüberzeugungen verbunden: Wer beobachtet, der affirmiert nicht. Aber auch die als Straftheorie im eigentlichen Sinne verstandene, also auf den internen Standpunkt des Rechtsanwenders bezogene Variante der positiven Generalprävention sinnt - jedenfalls auf den ersten Blick dem Rechtsanwender nicht an, sich mit den Vorstellungen der Bevölkerung über den Sinn der Strafe zu identifizieren. Der Rechtsanwender scheint sich vielmehr darauf beschränken zu können, die Existenz (und den etwaigen Wandel) dieser Vorstellungen als soziale Tatsachen zu konstatieren. ${ }^{85}$ Beachtung verdienen sie eben nicht wegen ihrer inhaltlichen Richtigkeit, sondern nur deshalb, weil angenommen wird, dass die Bestätigung des Rechtsbewusstseins der Gesellschaftsmitglieder zu einer inneren Festigung der betreffenden Gesellschaft führt.

Lässt diese Distanz sich unter dem Blickwinkel der spezifisch straftheoretischen Legitimationsfrage aber wirklich durchhalten ${ }^{36}$ Die Probleme werden sichtbar, sobald die Bevölkerung die Strafe aus Gründen befürwortet, die der betreffende Straftheoretiker von seiner Warte aus als „falsch“ bewerten muss. So nehmen die Vertreter der These von der „Prävention durch gerechte Vergeltung“ an, dass in der Bevölkerung eine starke Präferenz für eine retributive Strafbegründung bestehe. ${ }^{87}$ In diesem Fall kann nur ein im Wesentlichen nach Vergeltungsgrundsätzen operierendes Strafrecht die optimale Integrationswirkung entfalten. Von dem eigenen präventionstheoretischen Ausgangspunkt der betreffenden Autoren her betrachtet ist ein solches Begründungsmodell indessen irrational. Da sie es aber dennoch nicht ignorieren können, läuft ihre Posi-

deskriptiven Anlage dieser Konzeption ebd., S. 867). Näher dazu Michael PAwLiK, Das unerlaubte Verhalten beim Betrug, 1999, S. 62 ff. sowie KALOUS (Anm. 83), S. 108 f.; vgl. ferner NeumanN/SCHROTh (Anm. 16), S. 34 sowie NeUmanN (Anm. 83), S. 149.

85 In diesem Sinne bereits NowaKowski (Anm. 83), S. 85 ff.

86 Kritisch HeLmUt FrISTER, Die Struktur des „,voluntativen Schuldelements“. Zugleich eine Analyse des Verhältnisses von Schuld und positiver Generalprävention, 1993, S. 79 ff; Neumann (Anm. 83), Deutung, S. 404.

87 Vgl. etwa Dölling (Anm. 83), S. 15 f.; Kalous (Anm. 83), S. 249 ff.; MieHE (Anm. 83), S. 252; Morselli (Anm. 38), S. 230; Müller-DietZ (Anm. 83), S. 824; STRENG (Anm. 78), ZStW 92 (1980), S. 663. - In jüngerer Zeit wird dagegen nicht selten eine zunehmende Distanzierung der Bevölkerung von einem einseitig retributiven Verständnis der Strafe angenommen (vgl. FrehSEE [Anm. 16], S. 104; LÜDERSSEN [Anm. 59], S. 93, 414; GÜNTER STRATENwERTh, Die Zukunft des strafrechtlichen Schuldprinzips, 1977, S. 47); skeptisch dazu HoffmanN (Anm. 16), S. $130 \mathrm{f}$. 
tion auf das Ansinnen an den Verurteilten hinaus, sich um des gesellschaftlichen Friedens willen einem unvernünftig motivierten Zwang zu unterwerfen. ${ }^{88}$ Eine Pflicht, die Unaufgeklärtheit der eigenen gesellschaftlichen Umwelt duldend hinzunehmen, ließe sich freilich eher als Aufopferung denn als Strafe charakterisieren. ${ }^{89}$ Die Begründung dementiert hier das Begründungsziel.

Angesichts dieser prekären Situation scheint den Befürwortern der positiven Generalprävention nichts anderes übrig zu bleiben, als ihre legitimationstheoretischen Überlegungen $\mathrm{zu}$ verheimlichen bzw. den Mitgliedern des Rechtsstabes zu empfehlen, im Rahmen ihrer beruflichen Tätigkeit gleichsam mit gespaltener Zunge zu sprechen. ${ }^{90} \mathrm{Um}$ dem eigentlichen Interesse der Bevölkerung, der Befestigung des sozialen Friedens, zu dienen, sollten sie so tun, als teilten sie deren - wie ihnen bewusst ist: in Wahrheit unvernünftiges - Interesse an Vergeltung. „Um der Nützlichkeit willen wird ein System öffentlicher Unwahrheit propagiert. “91 Der Preis, der für diese Hilfsstrategie gezahlt werden müßte, ist jedoch inakzeptabel hoch: Es würde nicht nur (wie bei der negativen Generalprävention) dem Verurteilten, sondern der gesamten „unaufgeklärten“ Bevölkerung die kommunikative Gleichheit abgesprochen. ${ }^{92}$ Statt die legitimationstheoretischen Defizite der negativen Generalprävention abzubauen und - wie HASSEMER meint - die Menschen ernst zu nehmen ${ }^{93}$ würde die Lehre von der positiven Generalprävention diese Defizite sogar noch vergrößern.

88 So ausdrücklich Ebert (Anm. 78), S. 52 f. und HAFFKe (Anm. 78), S. 85.

89 An dieser kategorialen Unangemessenheit würde auch die von GÜNTER ELLSCHEID/ WINFRIED HASSEMER, Strafe ohne Vorwurf. Bemerkungen zum Grund strafrechtlicher Haftung, in: Klaus Lüderssen/Fritz Sack (Hrsg.), Abweichendes Verhalten, Bd. II, 1975, S. 266, 287 zur Bändigung des ,,irrationalen Vergeltungsbedürfnis[ses] der Gesellschaft" vorgeschlagene Heranziehung des Verhältnismäßigkeitsprinzips oder die von STRATENWERTH (Anm. 50), S. 918 eingeforderte Verknüpfung der strafrechtlichen Sanktion mit dem Angebot von Hilfe nichts ändern.

90 Die diesbezügliche Problematik ist erstmals von BOCK thematisiert worden; vgl. DENS. (Anm. 15), ZStW 103 (1991), S. 649 ff.; DENS. (Anm. 15), JuS 1994, S. 97 f. Ebenso Frister (Anm. 86), S. 81, 97; TATJANA HÖRnLE, Tatproportionale Strafzumessung, 1999, S. 118; Tatjana Hörnle/Andrew von Hirsch, Positive Generalprävention und Tadel, in: Bernd Schünemann u.a. (Hrsg.), Positive Generalprävention. Kritische Analysen im deutsch-englischen Dialog, 1998, S. 53, 89 f.; SUSANNE PielsTiCKeR, $\int$ 46a StGB: Revisionsfalle oder sinnvolle Bereicherung des Sanktionenrechts?, 2004, S. 63; PRiTTWITZ (Anm. 16), S. 235.

91 Wolff (Anm. 26), S. 803.

92 Bock (Anm. 15), JuS 1994, S. 97; Neumann (Anm. 83), Kritik, S. 147.

93 Vgl. Hassemer (Anm. 78), Variationen, S. 37. 


\section{Vergeltung als Strafzweck}

\section{Strafe als Schadenersatz}

Die Mängel der Präventionslehren legen es nahe, dem Versuch einer vergeltungstheoretischen Straflegitimation eine neue Chance einzuräumen. Dem entspricht die Entwicklung, die die wissenschaftliche Diskussion in den letzten Jahren genommen hat. In einem Vortrag aus dem Jahre 1979 merkte ARMIN KAUFMANN noch an, mit dem Wort Vergeltung werde eine Position weniger markiert als vielmehr gebrandmarkt. ${ }^{94}$ Seither sind jedoch zahlreiche Stimmen laut geworden, die retributiven Überlegungen eine zentrale Rolle im Rahmen der Strafbegründung einräumen. ${ }^{95}$ SCHÜNEMANN - wahrlich kein Freund des Vergeltungsdenkens - spricht gar von einer „Renaissance der absoluten Straftheorie ". ${ }^{96}$ Auch das Bundesverfassungsgericht rückt in seiner neueren Rechtsprechung den Vergeltungsaspekt wieder stärker in den Vordergrund. ${ }^{97}$ Zwar hat das Gericht dem Strafzweck der Vergeltung niemals die Berechtigung abgesprochen. ${ }^{98}$ In seinem Urteil von 1977 über die Verfassungsmäßigkeit der lebenslangen Freiheitsstrafe bei Mord hat es aber eindeutig die präventiven Strafzwecke in den Mittelpunkt seiner Erörterungen gestellt. ${ }^{99}$ Deutlich anders ist die Akzentsetzung dagegen in den Urteilen des Bundesverfassungsgerichts zur Strafbarkeit der Mauerschützen ${ }^{100}$ und zur Sicherungsverwahrung: „Strafe“ - so heißt es in der letztgenannten, 2004 ergangenen Entscheidung - ,,gilt als Ausdruck vergeltender Gerechtigkeit und ist damit Reaktion auf ein normwidriges Verhalten.“101 Die Strafe sei ,eine repressive Übelzufügung als Reaktion auf schuldhaftes Verhalten, die dem Schuldausgleich dient." ${ }^{102}$ Kurzum:

94 KaUfManN (Anm. 62), S. 265.

95 Nachweise bei PAWLIK (Anm. 6), S. 45 f. - Dies gilt erst recht für den angloamerikanischen Raum. Der Retributivismus wird dort als die führende Straftheorie bezeichnet (vgl. Kalous [Anm. 83], S. 173). Darstellungen des Meinungsspektrums bei HANNO KAISER, Widerspruch und harte Behandlung. Zur Rechtfertigung von Strafe, 1999, S. 134 ff. und KALOUS a.a.O., S. $173 \mathrm{ff}$.

96 BERnd schünEmANN, Aporien der Straftheorie in Philosophie und Literatur, in: Cornelius Prittwitz u.a. (Hrsg.), Festschrift für Klaus Lüderssen zum 70. Geburtstag, 2002, S. 327.

97 Insgesamt spielt die Strafzweckfrage innerhalb der Judikatur des Bundesverfassungsgerichts allerdings nur eine sehr eingeschränkte Rolle; dazu APPEL (Anm. 15), S. 73 ff.; OtTo Lagodny, Strafrecht vor den Schranken der Grundrechte, 1995, S. 310 ff.

98 Vgl. BVerfGE 21, S. 391, 403 f.; BVerfGE 22, S. 125, 132; BVerfGE 27, S. 36, 42; BVerfGE 28, S. 264, 278; BVerfGE 45, S. 187, 253 ff.; BVerfGE 64, S. 261, 271; BVerfGE 95, S. 96, 140; BVerfGE 109, S. 133, 168.

99 Vgl. BVerfGE 45, S. 187, 253 ff.

100 BVerfGE 99, S. 96, 140 f.

101 BVerfGE 109, S. 133, 168.

102 BVerfGE 109, S. 133, 173 f. 
Vergeltung wird wieder als ernstzunehmender, ja womöglich tragender Strafzweck anerkannt.

Näher betrachtet, ist diese Entwicklung weniger überraschend, als sie zunächst erscheint. Die bislang letzte ,harte“ Präventionstheorie im deutschsprachigen Strafrechtsdiskurs war die Resozialisierungslehre, die Straftaten hauptsächlich als Indiz einer behandlungsbedürftigen sozialen Deprivation des Täters begriff. Schon die positive Generalprävention, namentlich in ihrer Variante als „Prävention durch gerechte Vergeltung“, wies eine unverkennbar kompromisshafte Struktur auf: Formal als Präventionslehre daherkommend, ermöglichte sie eine weitgehende Rezeption der traditionellen vergeltungstheoretischen Inhalte. Die wachsende Einsicht in die legitimationstheoretischen Probleme, die mit dieser zwiespältigen Konstruktion einhergehen, legte es nahe, auf die präventionstheoretische Verkleidung zu verzichten und sich offen zu dem vergeltungstheoretischen Inhalt zu bekennen. Zudem sind die Gefahren des Präventionsparadigmas zusehends deutlich geworden. Das Präventionsdenken kennt kein „Genug“: Jedwedes Sicherheitsniveau lässt sich immer noch weiter verbessern. In den Händen eines aktivistischen Gesetzgebers erwies sich der Präventionsgedanke deshalb als eine Art Generalschlüssel zur Strafbarkeitsausdehnung. ${ }^{103}$ Die wachsende Einsicht, dass das Präventionsparadigma kraft der ihm innewohnenden Expansionslogik das Strafrecht (und nicht zuletzt auch das Strafverfahrensrecht) seiner disziplinären Identität zu berauben und es in ein umfassendes Regime der Gefahrenbekämpfung und Verhaltenslenkung einzugliedern droht, kurz: die Besorgnis, dass das Strafrecht auf den Status zurückfallen könnte, den es im spätabsolutistischen Wohlfahrtsstaat innehatte, ${ }^{104}$ ist womöglich das stärkste movens für das neuerwachte Interesse am Vergeltungsgedanken. ${ }^{105}$

103 Analysen dieses Prozesses finden sich etwa bei Appel (Anm. 15), S. 34 ff. und WINFRIED HASSEMER, Sicherheit durch Strafrecht, in: Institut für Kriminalwissenschaften Frankfurt a. M. (Hrsg.), Jenseits des rechtsstaatlichen Strafrechts, 2007, S. 99, 103 ff.; für ein aktuelles Beispiel: Michael Pawlik, Der Terrorist und sein Recht, 2008, S. 25 ff.

104 Dazu Martin Reulecke, Gleichheit und Strafrecht im deutschen Naturrecht des 18. und 19. Jahrhunderts, 2007, S. $143 \mathrm{ff}$.

105 Exemplarisch ist insofern die Position HASSEMERS. Während dieser in einer Arbeit aus dem Jahre 1983 noch die wissenschaftliche sowie die kriminalpolitische Dignität der absoluten Straftheorie in Abrede gestellt hatte (HASSEMER [Anm. 16], Strafziele, S. $48 \mathrm{f}$.), rief er sieben Jahre darauf in einer vielzitierten Wendung dazu auf, die „Weisheit“ der Lehren von der Tatvergeltung wiederzuentdecken (HASSEMER [Anm. 78], Einführung, S. 323 f.). Die Tatvergeltung bilde den Kern jenes Konzepts der Formalisierung, welches Strafrecht und Strafe als ein Muster humanen Umgangs mit der Abweichung sozial vermitteln sollten (a.a.O., S. 327). Präventive Strafbegründung ohne Gegenstück aus den absoluten Straftheorien wäre „rechtsstaatlich unerträglich“ (HASSEMER [Anm. 78], Festschrift Lüderssen, S. 226). - Den „liberale[n] Gehalt des Vergeltungsgedankens“ betont auch ANDREAS MOSBACHER, Kant und der „Kanniba- 
Dass Vergeltungslehren über geraume Zeit auf dem Markt der Meinungen einen schweren Stand gehabt haben, überrascht freilich nicht. Sie sind von ernstem und rauhem Aussehen; ihnen geht die funktionale Glätte ab, mit der die Präventionslehren für sich einzunehmen wissen. Hören wir nochmals FRIEDRICH JULIUS STAHL: „Die Strafe kann keinen bloß zukünftigen Zweck haben (daß künftig keine Verbrechen geschehen), und kein bloß faktisches mechanisches Mittel seyn; sondern die vollbrachte That selbst und schlechthin fordert aus ethischem Grunde die Strafe." ${ }^{106}$ Die Bedeutung der Strafe kann deshalb ,keine andere seyn [...], als die, daß sie die nothwendige Folge des Verbrechens ist nach der Gerechtigkeit." ${ }^{107}$

STAHL, der sich so nachdrücklich zur Vergeltungstheorie bekennt, weiß freilich sehr wohl um die zentrale Schwierigkeit dieses Modells der Strafbegründung: „Wie kann eine Wiederherstellung der verletzten Ordnung darin liegen, daß dem Verletzer ein Uebel zugefügt wird, was die Strafe unläugbar ist? Dadurch, daß ein zweites Uebel in die Welt kömmt, ist nicht der Widerspruch, den das erste enthält, aufgehoben." ${ }^{108}$

STAHL greift hier auf eine Erwägung zurück, der einige Jahrzehnte zuvor HEGEL beredten Ausdruck verliehen hat: Es sei unvernünftig, ein Übel bloß deshalb zu wollen, weil schon ein anderes Übel vorhanden sei. ${ }^{109}$ HEGELS Schüler EDUARD GANS kommentiert: ,Wenn das Verbrechen schon ein Übel ist, weshalb soll dieses dann noch durch ein anderes Übel, die Strafe, vermehrt werden?" 110

Wenn HEGEL, GANS und STAHL sich trotzdem zum Retributionsgedanken bekennen, setzen sie offenbar voraus, dass es eine Version der Vergeltungstheorie gibt, die sich nicht in der Aneinanderreihung zweier Übel erschöpft. ${ }^{111}$ Die Gerechtigkeit, so fasst STAHL diese Überlegung zusammen, bestehe ,nicht darin, daß Uebel in die Welt komme, sondern darin, daß die Herrschaft der sittlichen Macht im sittlichen Reiche unverbrüchlich erhalten werde“. ${ }^{112}$ Handele der Mensch gegen das Gesetz, so nehme er sich eine Herrschaftsmacht („Herrlichkeit“) heraus, die der sittlichen Macht, der er gehorchen solle, widerspreche. Indem die vom Delinquenten usurpierte Hand-

le“, in: B. Sharon Byrd u.a. (Hrsg.), Jahrbuch für Recht und Ethik, Bd. 14 (2006), S. 479, 491.

106 Friedrich Julius Stahl, Die Philosophie des Rechts, Bd. II/1 (Die allgemeinen Lehren und das Privatrecht), 5. Aufl. 1878, Nachdruck 1963, S. 167.

107 STAHL (Anm. 1), Bd. II/2, S. 683.

108 Stahl (Anm. 106), Bd. II/1, S. 165 f.

109 GeOrg Wilhelm Friedrich Hegel, Grundlinien der Philosophie des Rechts, hrsg. von Eva Moldenhauer/Karl Markus Michel, 1986, \99 (S. 187).

110 EDUARD GANS, Naturrecht und Universalrechtsgeschichte, hrsg. von Johann Braun, 2005, S. 110.

111 Eine eindringliche Darstellung von Hegels Straftheorie gibt Michael Ramb, Strafbegründung in den Systemen der Hegelianer, 2005, S. 16 ff.

112 STAHL (Anm. 106), Bd. II/1, S. 166. 
lungsmacht sich an der „,höhere[n] Herrlichkeit der sittlichen Macht ${ }^{\text {“113 }}$ breche, werde auf reale Weise bekundet, dass die sittliche Ordnung der Herr sei. „So muß das Böse selbst, indem es zu Boden gedrückt wird, zur Verherrlichung der sittlichen Macht dienen. " ${ }^{114}$ Entkleidet man diese Konzeption ihres Pathos, so wird auf ihrem Grund der Gedanke des Schadenersatzes sichtbar. Danach ist derjenige, der einen Schaden herbeigeführt hat, dazu verpflichtet, sein destruktives durch ein konstruktives Tun auszugleichen: Er hat dafur Sorge zu tragen, dass der vorige Zustand, soweit möglich, wiederhergestellt wird. ${ }^{115}$ Dieser Erscheinungsform der ausgleichenden Gerechtigkeit kann man nicht vorwerfen, sie erschöpfe sich in einer negativen Sequenz zweier Übel. Der Delinquent erbringt vielmehr eine positive Leistung, indem er durch die Duldung der Strafe dazu beiträgt, den von ihm gestörten Zustand stabiler Rechtlichkeit $\mathrm{zu}$ restituieren und $\mathrm{zu}$ festigen.

Strafe als Schadenersatz - damit ist also, auf eine kurze Formel gebracht, der Weg bezeichnet, auf dem sich dem Sinnlosigkeitsverdikt gegen die vergeltungstheoretische Strafbegründung entkommen lässt. Dieser Ansatz war im 19. Jahrhundert keineswegs auf den Kreis der strafrechtlichen HEGEL-Schüler oder konservative Staatsdenker wie STAHL beschränkt; eine detaillierte Lehre vom „intellektuellen Verbrechensschaden“ entwickelte beispielsweise THEODOR WELCKER, einer der bedeutendsten Repräsentanten des deutschen Frühliberalismus und alles andere als ein orthodoxer Hegelianer. ${ }^{116}$ Im 19. Jahrhundert hat sich dieser Gedanke allerdings nicht durchsetzen können. Verantwortlich dafür war zum einen die Konturlosigkeit vieler Verbrechensschadentheorien ${ }^{117}$ und zum anderen der Zeitgeist, der auf einer strikten kategorialen Trennung des Strafrechts vom Zivilrecht bestand. Selten, so stellte etwa BINDING 1872 mit gewohntem rhetorischen Schwung fest, sei eine unglücklichere Analogie

113 STAHL (Anm. 106), Bd. II/1, S. 166.

114 STAHL (Anm. 106), Bd. II/1, S. 167.

115 Vgl. die Motive zu dem Entwurfe eines Bürgerlichen Gesetzbuches für das Deutsche Reich, Bd. 2, 1896, S. 20 („Prinzip der Wiederherstellungspflicht“). Dem Ausgleichsgedanken wird auch in der heutigen schadenersatzrechtlichen Literatur eine zentrale Bedeutung eingeräumt (vgl. etwa HaRtmut OetKeR, in: Kurt Rebmann u.a. [Hrsg.], Münchener Kommentar zum Bürgerlichen Gesetzbuch, Bd. 2, 5. Aufl. 2006, \ 249 Rn. 8; Josef Esser/Eike SCHMidT, Schuldrecht, Bd. I/2, 8. Aufl. 2000, S. 172); mitunter wird er explizit auf die Idee der ausgleichenden Gerechtigkeit zurückgeführt (so GotTfRied SCHIEmanN, in: Michael Martinek [Hrsg.], Staudinger. Kommentar zum Bürgerlichen Gesetzbuch mit Einführungsgesetz und Nebengesetze. Zweites Buch. Recht der Schuldverhältnisse. S\$ 249-254, 14. Aufl. 2005, Vorbem. zu \\$ 249 ff. BGB, Rn. 3).

116 Näher zu Welckers Theorie: PAwlik (Anm. 6), S. 59 ff. - Über Welckers geistesgeschichtliche Stellung: Michael Adalbert Kotulla, Art. „Vormärz“, in: Wolfgang Erler u.a. (Hrsg.), Handwörterbuch zur deutschen Rechtsgeschichte, Bd. 5, 1998, Sp. 1046; Reulecke (Anm. 104), S. 263 ff.; RAiner Schöttle, Politische Theorien des süddeutschen Liberalismus im Vormärz, 1994, S. 115 ff.

117 Dazu PaWlik (Anm. 6), S. 60 f. 
als die von den Wirkungen des Ersatzes auf die der Strafe gezogen worden. ${ }^{118}$ „Die Strafe soll eine Wunde schlagen, der Schadenersatz eine andere heilen“ darin bestehe der „Kern des Unterschiedes zwischen Strafe und Ersatz. “119 Nach BINDINGS Attacke galt die Lehre vom Verbrechensschaden als wissenschaftlich erledigt. Jedoch war das Vorbringen BINDINGS offenkundig unzureichend. Eine Strafe, deren Sinn sich darin erschöpfte, dem Delinquenten zur Vergeltung seiner eigenen Untat ebenfalls eine Wunde zu schlagen, ließe sich nach dem oben Ausgeführten schlechterdings nicht legitimieren. Der Lösungsansatz HEGELS versteht sich allerdings gerade als Antwort auf diesen Einwand; die Polemik BINDINGS wird ihm deshalb nicht gerecht. Freilich ist nach einer treffenden Wendung FEUERBACHS ,eine Metapher kein Philosophem“"120 und, nunmehr mit RICHARD SCHMIDT ${ }^{121}$ gesprochen, ein ,,mehr oder minder glücklich gewähltes Gleichnis“ noch kein dogmatisch belastbarer Begriff. Ist die Parallelisierung von Strafe und Schadenersatz tragfähig? Oder führt sie, indem sie eine Schwierigkeit des Vergeltungsparadigmas zu überwinden verspricht, an anderen Stellen zu weitaus schwerer wiegenden Problemen (2./3.)? Und wie lässt sich auf ihrer Grundlage die intrikate Verknüpfung von Strafe und Schmerz begründen (4.)?

\section{Verbrecherisches Unrecht als Mitwirkungspflichtverletzung}

Zwischen Strafe und Schadenersatz bestehen unübersehbare Unterschiede. Der zivilrechtliche Schadenersatz dient dem Ausgleich des Schadens, den das einzelne Opfer einer Vertragsverletzung oder einer unerlaubten Handlung erlitten hat. Der Strafe ist es hingegen eigen, dass sie den Konflikt zwischen dem Täter und dem Verletzten ,entprivatisiert" "122: Dem Verurteilten wird ein Übel zugefügt, ohne dass dem Opfer daraus ein unmittelbarer Vorteil erwachsen würde. Häufig erschwert oder vereitelt die Bestrafung des Täters sogar die Chance des Opfers, für seinen Schaden einen Ausgleich zu erlangen. ${ }^{123}$ Diese Hintanstellung der spezifischen Opferinteressen ist das Ergebnis einer mehrere Jahrhun-

118 KARL Binding, Die Normen und ihre Übertretung. Eine Untersuchung über die rechtmäßige Handlung und die Arten des Delikts, Bd. 1: Normen und Strafgesetze, 3. Aufl., Leipzig 1916, Nachdruck 1965, S. 275.

119 BiNDING (Anm. 118), S. 288.

120 FEUERBACH (Anm. 2), S. 92.

121 SCHMID (Anm. 64), S. 70.

122 Appel (Anm. 15), S. 448, 461.

123 Seine klassische Formulierung findet dieser Einwand bei BINDING (Anm. 118), S. 286. - Zuletzt GÜNTER BEMmANN, Täter-Opfer-Ausgleich im Strafrecht, JR 2003, S. 227; Claus Roxin, Strafe und Wiedergutmachung, in: Thomas Rauscher/Heinz-Peter Mansel (Hrsg.), Festschrift für Werner Lorenz zum 80. Geburtstag, 2001, S. 51, 53 f. 
derte währenden Entwicklung. ${ }^{124}$ Als „Entmachtung der emotionalen Gewalt des verletzten Gemüts“125 ermöglichte die „Neutralisierung des Opfers“"126 die spezifische Rationalität des neuzeitlichen Straf- und Strafverfahrensrechts ${ }^{127}$ und schärfte den Blick für die Schutzbedürfnisse des Beschuldigten. ${ }^{128}$

Ist aber die Strafe gerade nicht ein Opfer, das der Täter „,dem Verletzten bringt" "129, dann kann auch das Unrecht, welches sie vergilt, nicht allein ein Unrecht dem Verletzten gegenüber, eine Verletzung seiner Rechtsgüter, sein. Wären Delikte wie Totschlag, Raub oder Betrug ihrem materiellen Gehalt nach nichts weiter als pflichtwidrig herbeigeführte Verletzungen von Rechtsgütern einer Person, dann ließe sich nicht begründen, inwiefern die ,überindividuelle" Strafe diese Verletzung sollte ausgleichen können. Straftat und Strafe vollzögen sich vielmehr innerhalb unterschiedlicher Rechtsverhältnisse. Wer eine interpersonale Deutung des Verbrechens mit einer Vergeltungstheorie der Strafe zu verbinden sucht, dem bleibt, wenn er konsequent ist, deshalb nur die Möglichkeit, die Vergeltung als Selbstzweck auszugeben. Will er dies nicht dass er es vernünftigerweise nicht wollen kann, wurde vorstehend gezeigt -, so bleibt ihm nichts anderes übrig, als sein Verbrechensverständnis einer Revision zu unterziehen. Auf dem Wege der Strafe lässt sich danach nur ein solches Unrecht ausgleichen, das statt als bloße Beeinträchtigung des konkreten Opfers als Angriff auf die Rechtsgemeinschaft als Ganze, repräsentiert durch den zur Setzung von Strafnormen befugten Gesetzgeber, begriffen wird: als Verletzung der den Täter gegenüber der Allgemeinheit treffenden Pflicht, sich an der Aufrechterhaltung eines Zustandes der Rechtlichkeit zu beteiligen.

Mit dem Befund, dass man das Verbrechen in dieser Weise verstehen muss, wenn man die Strafe vergeltungstheoretisch legitimieren will, ist freilich noch nicht bewiesen, dass diese Deutung für sich genommen zu überzeugen vermag. Auf diese Frage werde ich im Folgenden näher eingehen. Vorab möchte ich aber eines klarstellen: Mit der Deutung des Verbrechens als Verletzung einer Mitwirkungspflicht gegenüber der Rechtsgemeinschaft ist keineswegs gesagt, dass die Belange, um derentwillen dem Täter jene Pflicht auferlegt wird, ihrerseits ebenfalls durchgängig der Allgemeinheit zugeordnet werden müssten. Die Frage nach dem Legitimationsgrund der Mitwirkungspflicht ist von derjenigen nach der pflichtentheoretischen Struktur des Verbrechensbe-

124 Näher dazu Thomas Weigend, Deliktsopfer und Strafverfahren, 1989, S. 79 ff.; Wanja ANDreas Welke, Die Repersonalisierung des Rechtskonflikts, 2008, S. 256 ff.

125 WelKe (Anm. 124), S. 259.

126 Peter-Alexis Albrecht, Kriminologie: Eine Grundlegung zum Strafrecht, 3. Aufl. 2005, \$ 45 A (S. 361), B (S. 362).

127 Weigend (Anm. 124), S. $215 \mathrm{ff}$.

128 WeLKe (Anm. 124), S. 259 f., 284.

129 So aber ERNST-JOACHIM LAMPE, Recht und Moral staatlichen Strafens, in: Heike Jung u.a. (Hrsg.), Recht und Moral. Beiträge zu einer Standortbestimmung, 1991, S. $305,311$. 
griffs unabhängig; die Konstruktion des Verbrechensbegriffs präjudiziert nicht die legitimationstheoretische Problematik. Spätestens seit ROUSSEAU und KANT ist der Gedanke der Freiheit der unhintergehbare Fixpunkt aller philosophisch satisfaktionsfähigen Auseinandersetzungen mit praktischen Fragen. Als tragender Grund der Mitwirkungspflicht kommt demnach nur der Umstand in Betracht, dass es ihrer bedarf, um einen Zustand der Freiheitlichkeit aufrechtzuerhalten. Es ist diese Verknüpfung des Mitwirkungspflichtgedankens mit dem Gedanken der Wahrung personaler Freiheit, ${ }^{130}$ die meines Erachtens den Geltungsanspruch des Strafrechts rechtfertigt.

\section{Legitimationsgrund der Mitwirkungspflicht: Aufrechterhaltung eines Zustandes der Freiheitlichkeit}

Menschen haben ihr Leben nicht einfach, sondern sie führen es im Lichte ihrer eigenen Vorstellungen von einem guten und gelingenden Dasein. „Wir versuchen, in unserer zeitlich ausgedehnten Existenz eine Persönlichkeit zu entwickeln und Pläne zu verwirklichen, in denen sich manifestiert, wer wir sein und was wir erreichen wollen. "131 Die Hochschätzung von Selbstbestimmung und Selbstverwirklichung ist untrennbar mit der Struktur moderner Gesellschaften verknüpft, die sich zwischen dem 17. und dem 19. Jahrhundert herausbildete: dem Übergang von stratifikatorischer zu funktionaler Differenzierung. ${ }^{132}$ In stratifizierten Gesellschaften - Adelsgesellschaften - wird „die Gesellschaft als Rangordnung repräsentiert" ${ }^{133}$ Die Schichtzugehörigkeit wirkt hier multifunktional: Sie bündelt Vorteile bzw. Benachteiligungen in so gut wie allen Funktionsbereichen der Gesellschaft. ${ }^{134}$ In funktional differenzierten Gesellschaften verzichtet das Gesamtsystem demgegenüber auf jede Vorgabe einer Ordnung der Beziehung zwischen den Funktionssystemen. ${ }^{135}$ Die Rolle, die ein Individuum in einem Funktionssystem spielt, ist deshalb grundsätzlich entkoppelt von den Rollen, die es in anderen Funktionssystemen einnimmt. Was den teilbar gewordenen Individuen in dieser Situation für sich selbst bleibt, ist das Problem ihrer Identität ${ }^{136}$ und damit eine höchst anspruchsvolle Koordinations- und Integrationsaufgabe: Sie müssen die Verknüpfung ihrer verschiedenen sozialen Rollen (von denen keine sie in Gänze bestimmt) nunmehr selbst

130 Sie wird zu Recht eingefordert von Ralf Poscher, Am Fuße der Kathedrale, in: Matthias Jestaedt/Oliver Lepsius (Hrsg.), Rechtswissenschaftstheorie, 2008, S. 105, 110.

131 Michael Quante, Person, 2007, S. 147.

132 Niklas LuHManN, Gesellschaftsstruktur und Semantik, Bd. 1, 1980, S. 72 ff.

133 Niklas LuHManN, Die Gesellschaft der Gesellschaft, Bd. 2, 1997, S. 679.

134 LUHMANN (Anm. 133), S. 679.

135 LUHMANN (Anm. 133), S. 746.

136 NikLas LuHManN, Gesellschaftsstruktur und Semantik, Bd. 3, 1989, S. 223. 
leisten, ${ }^{137}$ sich also in einer vorneuzeitlich gänzlich undenkbaren Weise als Subjekte ihres Lebens verstehen.

Ein solches Subjekt - „die Welt, gesehen von einem Punkte aus, in sich realisiert und dadurch anderen zugänglich gemacht" - kann sich, wie LUHMANN ${ }^{138}$ hervorhebt, „nur im Reiche der Freiheit realisieren; sonst wäre es weder selbständig dargestellt noch einzigartig." Diese Idee sozial freigesetzter Subjektivität ist es denn auch, die den Kern des Begriffs der Menschenwürde ausmacht. Wie die Philosophen CHRIsTOPH MENKE und ARND POLLMANN jüngst gezeigt haben, besteht die Menschenwürde danach darin, dass jeder Mensch es verdient (oder eben: würdig ist), gleichermaßen als ein zur frei verantwortlichen Lebensführung berufenes Subjekt geachtet zu werden. ${ }^{139}$ Das Recht, zumal das Strafrecht, hat seine Hauptaufgabe deshalb darin, das Anliegen, jedermann solle sein Leben nach eigener Einsicht führen können, abzusichern. Zwar kann das Strafrecht dem Einzelnen kein erfülltes Leben garantieren. Was es aber vermag, ist dies: ihm, selbstverständlich unter der Bedingung strikter Wechselseitigkeit, eine von Fremdbestimmung freie Gestaltung des eigenen Daseins zu ermöglichen. ${ }^{140}$

137 LUHMANN (Anm. 136), S. 235.

138 LUHMANN (Anm. 136), S. 214.

139 Christoph Menke/Arnd Pollmann, Philosophie der Menschenrechte, 2007, S. 160.

140 Ebenso KÖHLER (Anm. 38), Strafrecht Allgemeiner Teil, S. 28 f.; DERS. (Anm. 38), Begriff, S. 67 ff.; DERS., Freiheitliches Rechtsprinzip und Betäubungsmittelstrafrecht, ZStW 104 (1992), S. 3, 15 ff.; WolfF (Anm. 26), S. 818 ff. - Im Unterschied zu dem hier in Übereinstimmung mit dem liberalen Standardmodell gewählten Ausgang vom Begriff des subjektiven Rechts ging die ältere naturrechtliche Tradition, wie sie maßgeblich von PufEndorf verkörpert wird, vom Primat der Pflicht aus (HORST DenZer, Moralphilosophie und Naturrecht bei Samuel Pufendorf, 1972, S. 86 ff.): Nicht dem Recht, sondern der Pflicht des Menschen und des Bürgers nach dem Gesetz der Natur - so der Titel von PUFENDORFS berühmtem Einführungswerk - galt das vorrangige Interesse der naturrechtlichen Autoren. Diese Konstruktion ermöglichte es ihnen, die jedem Recht innewohnende Gemeinwohlbindung besonders hervorzuheben. So muss nach PUfENDORF der Reiche demjenigen, der sich ohne eigene Schuld in Not und Elend befindet, aufgrund der allgemeinen Verpflichtung zu menschlichem Verhalten zur Hilfe kommen - eine Verpflichtung, die äußerstenfalls sogar einen Mundraub rechtfertige (PUFENDORF [Anm. 20], I/5, \ 23 [S. 70]). Gegenüber dem Staat habe der Bürger die Pflicht, „nichts höher zu veranschlagen als dessen Sicherheit und Wohl, Leben, Hab und Gut und alle Mittel zu seiner Entfaltung bereitwillig zur Verfügung zu stellen, sowie alle Kräfte des Geistes und des Körpers auf die Vermehrung seines Glanzes und die Förderung seiner Wohlfahrt auszurichten“" (a.a.O., II/18, \ 4 [S. 211]). Das liberale Denken war zu derart weitreichenden Gemeinwohlvorbehalten nicht mehr bereit, weil es vorrangig auf die wohlstandssteigernde Kraft des Privatinteresses und auf innergesellschaftliche Selbstregulation setzte. Eine grundsätzliche Unvereinbarkeit dieser beiden Modelle der Konstruktion einer guten politischen Gemeinschaft lässt sich daraus aber nicht ableiten. Sie reflektieren lediglich eine Verschiebung 
Dieser Aufgabe vermag die Rechtsordnung nur gerecht zu werden, wenn sie - wie WELZEL formuliert - ,,wirklichkeitsgestaltende Kraft besitzt ${ }^{\text {“ }}{ }^{141}$ Nicht weniger energisch als HOBBES erblickt auch WELZEL die erste und wichtigste Aufgabe des Rechts darin, ,den offen oder immerfort latent drohenden Bürgerkrieg aller gegen alle zu überwinden oder niederzuhalten und durch eine das Leben aller sichernde Ordnung zu ersetzen. " ${ }^{142}$ Auf eine kurze Formel gebracht: Die rechtliche Ordnung hat die „Herrschaft der Normalität“ durchzusetzen. ${ }^{143}$ Normalität aber herrscht dann, wenn ,,die Voraussetzungen für Handlungserfolg und Glück, für existentielle Selbstentwicklung und ethische Selbstverwirklichung zur Selbstverständlichkeit geworden sind." 144 Ein Zustand rechtlicher Normalität erfordert somit mehr als eine abstrakte Normenordnung; der einzelne Bürger muss sich in ihm der Achtung seiner Rechtsstellung durch seine Mitbürger weitgehend sicher sein können. Von einer Summe einzelner Rechtserfahrungen unterscheidet sich ein solcher Zustand konkret-realer

sozialer Plausibilitätsmaßstäbe und - daraus folgend - der Darlegungs- und Begründungslasten.

141 Hans Welzel, Abhandlungen zum Strafrecht und zur Rechtsphilosophie, 1975, S. 282.

142 Welzel (Anm. 141), S. 282.

143 Wolfgang Kersting, Sozialstaatliche Freiheitsgefährdung, FAZ v. 07.06.2008, S. 15. - Mitunter wird das Recht zur Teilhabe an der demokratischen Willensbildung zum legitimierenden Grund strafrechtlicher Verpflichtungen erhoben (so KLAUS GÜNTHER, Schuld und kommunikative Freiheit, 2005, S. 245 ff. sowie URS KINDHÄUSER, Schuld und Strafe. Zur Diskussion um ein „Feindstrafrecht“, in: Andreas Hoyer u.a. [Hrsg.], Festschrift für Friedrich-Christian Schroeder zum 70. Geburtstag, 2006, S. 81, 89 ff.; kritisch zu GÜNTHERS Position Michael PAWLIK, Der Bürger möchte bestraft werden, FAZ v. 14.03.2005, S. 40). Bei aller Hochschätzung demokratischer Verfahren dürfte diese Auffassung indes auf einer Überschätzung des formellen Wahlakts beruhen. Von ungleich größerer Freiheitsrelevanz als das Recht, alle vier Jahre ein Kreuz auf einem Wahlzettel machen zu dürfen, ist für den Einzelnen die Aussicht, im Alltag zwischen den Wahlterminen sicher und in Frieden leben zu können. Die freiheitstheoretisch primäre Alternative lautet deshalb nicht: Demokratie oder Nicht-Demokratie, sie lautet vielmehr: bürgerlicher Zustand oder Naturzustand. Auch ein demokratischer Staat muss zunächst einmal Staat sein. Er muss mithin die Leistungen erbringen, welche von einem Staat erwartet werden - in erster Linie die Garantie des Friedens. An dieser Aufgabe wird er scheitern, solange die Gehorsamspflicht seiner Bürger im Zweifel steht. Die Gehorsamspflicht der Bürger muss deshalb an die Staatlichkeit des Staates anknüpfen, nicht erst an dessen demokratische Verfasstheit. Wie hier RAINER KELLER, $\mathrm{Zu}$ Weltrechtspflege und Schuldprinzip, in: Cornelius Prittwitz u.a. (Hrsg.), Festschrift für Klaus Lüderssen zum 70. Geburtstag, 2002, S. 425, 427 f.; grundlegend zum staatsphilosophischen Primat des Sicherheitsanliegens JOSEF ISENSEE, Das Grundrecht auf Sicherheit, 1983, S. 3 ff. (historisch), 17 ff. (systematisch). - Vor einer Überschätzung der Legitimationsfigur der Selbstgesetzgebung wird gewarnt in: MiCHAEL PAWLIK, Selbstgesetzgebung der Regierten: Glanz und Elend einer Legitimationsfigur, in: Jan C. Joerden/Roland Wittmann (Hrsg.), Recht und Politik, 2004, S. $115 \mathrm{ff}$.

144 KeRsting (Anm. 143), S. 15. 
Freiheitlichkeit vor allem durch seine Stabilität, seine Dauerhaftigkeit. ${ }^{145}$ Gleichsam den cantus firmus der neuzeitlichen politischen Philosophie bildet die Überzeugung, dass es zur Herstellung und Aufrechterhaltung eines Zustandes gesicherter Freiheitlichkeit der Institutionen, vor allem des Staates, bedarf. ${ }^{146}$ Unentbehrlichkeit ist freilich etwas anderes als Exklusivität. Der Glaube, die Aufrechterhaltung der äußeren Ordnung könne ausschließlich den darauf spezialisierten staatlichen Behörden überlassen werden - eine Ansicht, die sich bereits bei KANT findet ${ }^{147}$ und zeitweise geradezu zum Credo der „Hochmoderne" avancierte ${ }^{148}$-, ist indessen irrig. Keine Gesellschaft kann ausschließlich auf die Macht der Institutionen setzen, allein schon deshalb, weil deren Handlungskapazitäten sehr begrenzt sind. ${ }^{149}$ Die Verantwortung für die Aufrechterhaltung eines Zustandes der Freiheitlichkeit trifft deshalb auch jeden einzelnen Bürger unmittelbar. ${ }^{150}$ Wie der Philosoph VOLKER GERHARDT zu Recht hervorhebt, besitzen nicht nur Gesetzgebung und Rechtsprechung repräsentativen Charakter, sondern auch die alltägliche Rechtsbefolgung: „Das Gesetz repräsentiert die Verhaltenserwartung einer institutionellen Gemeinschaft, der Richter repräsentiert das Gesetz und der legal handelnde Bürger stellt exemplarisch die Geltung der Gesetze vor.“"151

Ein Angriff auf den Zustand der Freiheitlichkeit äußert sich deshalb darin, dass der Täter, indem er der strafrechtlichen Verhaltensordnung zuwiderhandelt, seine Rolle als Repräsentant der Rechtsgemeinschaft - kurz: als Bürger bricht. Damit hat der oben hypothetisch in den Raum gestellte Verbrechensbegriff die erforderliche legitimationstheoretische Stützung erhalten. Indem der Straftäter seine Pflicht verletzt, durch die Befolgung der strafrechtlichen Normen an der Aufrechterhaltung des bestehenden Rechtszustandes mitzuwirken, handelt er der „,ursprüngliche[n] Verbundenheit der im Gemeinwesen $\mathrm{Zu}$ -

145 PAWLIK (Anm. 6), S. 81.

146 So zuletzt auch Kersting (Anm. 143), S. 15.

147 Dazu Michael Pawlik, Kants Volk von Teufeln und sein Staat, in: B. Sharon Byrd u.a. (Hrsg.), Jahrbuch für Recht und Ethik, Bd. 14 (2006), S. 269 ff.

148 Vgl. David GARLAND, Kultur der Kontrolle, 2008, S. 92.

149 Näher PAWLIK (Anm. 147), S. 279 ff.

150 Dies bestreitet FRANK SALIGER, Feindstrafrecht: Kritisches oder totalitäres Strafrechtskonzept?, JZ 2006, S. 756, 762 mit der Behauptung, eine solche Position sei totalitär. Der Vorwurf geht fehl: Totalitär wäre im Gegenteil ein Staat, der Ernst damit machte, Normkonformität allein mit Hilfe seines Zwangsapparates zu sichern (näher PAWLIK [Anm. 147], S. 280 f.; ebenso GÜnTHER JAKOBS, Norm, Person, Gesellschaft, 3. Aufl. 2008, S. 78). - Im Wesentlichen wie hier Noll (Anm. 83), S. 14 f.; Peter SAladin, Verantwortung als Staatsprinzip, 1984, S. 70; JAN ZIEKOW, Eigenverantwortung als Verfassungsprinzip, in: Stefan Brink/Heinrich Amadeus Wolff (Hrsg.), Gemeinwohl und Verantwortung. Festschrift für Hans Herbert von Arnim zum 70. Geburtstag, 2004, S. 189, 203; im Ansatz auch Uwe MurmanN, Über den Zweck des Strafprozesses, GA 2004, S. 65, 70.

151 Volker Gerhardt, Partizipation, Das Prinzip der Politik, 2007, S. 343. 
sammengeschlossenen " zuwider. $^{152}$ Insofern stellt ein Verbrechen begrifflich ein Unrecht gegenüber der Rechtsgemeinschaft als Ganzes dar. ${ }^{153}$ Ihren Legitimationsgrund aber findet die strafbewehrte Mitwirkungspflicht in der personalen Freiheit der Bürger, die nur im Rahmen einer durchsetzungsfähigen Rechtsordnung zu realer Werthaltigkeit erstarkt.

Wie jede Theorie, so hat auch die hier vorgestellte Konzeption spezifische Begründungsgrenzen. Über die Legitimität der Tatbestände, deren Verletzung als ein dem Täter in seiner Bürgerrolle zurechenbares Unrecht behandelt wird, sagt sie nur so viel, dass auch diese Tatbestände freiheitstheoretisch legitimierbar sein müssen. Die Grenzen zulässiger Kriminalisierung näher zu bestimmen ist zwar ebenfalls eine höchst bedeutsame Aufgabe, aber eine andere als die unter dem Titel der „Straftheorie“ zu erörternde Problematik. ${ }^{154}$ Dieser Befund gilt für Vergeltungs- und Präventionstheorien der Strafe gleichermaßen. Ob eine Strafrechtsordnung es verdient, dass sie mit Hilfe von Abschreckung, der Einübung in Normtreue oder der Umerziehung von Delinquenten stabilisiert wird, ist eine Frage, die unabhängig von der Würdigung dieser Mittel selbst zu beantworten ist. ${ }^{155}$ Noch in einer weiteren Hinsicht übt die vorliegende Theorie sich in der Tugend der Selbstbescheidung. Ihr ist es lediglich um den Nachweis zu tun, dass keine prinzipiellen Bedenken dagegen bestehen, auf eine Tat, die sich nach den einschlägigen Regeln des materiellen Strafrechts als ein Unrecht des Bürgers deuten lässt, mit Strafe zu reagieren. Dies besagt aber keineswegs, dass jedes Unrecht des Bürgers mit einer Strafe geahndet werden

152 Treffend APPel (Anm. 15), S. 468. - Nahestehend WOLFGANG FRISCH, Unrecht und Schuld im Verbrechensbegriff und in der Strafzumessung, in: Guido Britz u.a. (Hrsg.), Grundfragen staatlichen Strafens. Festschrift für Heinz Müller-Dietz zum 70. Geburtstag, 2001, S. 237, 254; URS KINDHÄUSER, Rechtstreue als Schuldkategorie, ZStW 107 (1995), S. 701, 722; Claus Roxin, Sinn und Grenzen staatlicher Strafe, JuS 1966, S. 377, 385; WolfGang Schild, Strafbegriff und Grundgesetz, in: Albin Eser u.a. (Hrsg.), Festschrift für Theodor Lenckner zum 70. Geburtstag, 1998, S. 287, 305 f.; RAINER ZACZYK, Staat und Strafe. Bemerkungen zum sogenannten „Inselbeispiel” in Kants Metaphysik der Sitten, in: Götz Landwehr (Hrsg.), Freiheit, Gleichheit, Selbständigkeit. Zur Aktualität der Rechtsphilosophie Kants für die Gerechtigkeit in der modernen Gesellschaft, 1999, S. 73, 80 ff.

153 Dies hat auch Konsequenzen für das Strafverfahrensrecht: Die Rechte und Garantien der Verfahrensbeteiligten werden danach nicht zur Sicherung eigenständiger Individualinteressen eingeräumt, sondern ordnen sich im Gegenteil in das Verfahren der Normbestätigung ein und haben ,die - mit Blick auf das Gesamtmodell untergeordnete - Aufgabe, zu verhindern, daß die Normrehabilitierung um jeden Preis betrieben wird“ (APPel [Anm. 15], S. 465 f.). Näher dazu Michael PAwLiK, Verdeckte Ermittlungen und das Schweigerecht des Beschuldigten, GA 1998, S. 378, $380 \mathrm{ff}$.

154 Ebenso Appel (Anm. 15), S. 442; KAlous (Anm. 83), S. 117; KindHÄUSER (Anm. 83), GA 1989, S. 493.

155 Appel (Anm. 15), S. 442; BeCK (Anm. 16), S. 39 ff.; HAfFKe (Anm. 78), S. 82; JAKOBS (Anm. 61), 1/18; JescheCK/ Weigend (Anm. 63), \$ 8 II 3 (S. 68); Kalous (Anm. 83), S. 117; Müssig (Anm. 78), S. 142 f. 
muss. ${ }^{156}$ Eine gefestigte Gesellschaft wird nicht nur zu einer erheblichen Milderung der Strafen tendieren. Sie kann es sich auch leisten, die Reaktionsform der Strafe schwerwiegenden Beeinträchtigungen der Daseinsbedingungen von Freiheit vorzubehalten, weniger gewichtige Unrechtstaten hingegen auf andere Weise - etwa durch die Verpflichtung des Täters zur Wiedergutmachung - zu beantworten. ${ }^{157}$ In einem Wort: Die hiesige Konzeption erhebt lediglich den Anspruch einer Strafermöglichungs-, aber weder denjenigen einer Kriminalisierungs- noch denjenigen einer Straferzwingungstheorie. ${ }^{158}$

\section{Strafe und Schmerz}

Der Täter eines Verbrechens verletzt nach dem vorstehend Ausgeführten seine Bürgerpflicht, an der Aufrechterhaltung des bestehenden Zustandes der Rechtlichkeit mitzuwirken, und beeinträchtigt oder bedroht dadurch die anderen Personen zustehenden Freiheitsräume. Seine Unrechtstat ändert freilich nichts daran, dass der Straftäter Bürger ist und bleibt; deshalb wird er aus seiner Verantwortung für das Gelingen des Projekts einer wirklichkeitshaltigen Freiheitsordnung nicht entlassen. ${ }^{159}$ Lediglich der Inhalt seiner Verpflichtung wandelt sich. Der legal handelnde Bürger trägt zur Stabilisierung eines Zustandes realer Freiheitlichkeit dadurch bei, dass er den anderen das Ihrige an Freiheit beläßt. Im Falle des Straftäters wandelt sich die primäre Erfüllungspflicht zu einer sekundären Duldungspflicht: Weil der Delinquent dem Grundaxiom aller Rechtlichkeit - dem Satz, dass es gesicherte Freiheit nur um den Preis der

156 Dem verbreiteten und berechtigten Einwand gegen eine als „absolute“ Theorie im traditionellen Sinne verstandene Vergeltungslehre, ihr zufolge müsse die Strafe dem Normbruch kategorisch folgen (beispielhaft HEINRICH HENKEL, Einführung in die Rechtsphilosophie. Grundlagen des Rechts, 2. Aufl. 1977, S. 411 f.; DERS. [Anm. 83], S. 8; JAKOBS [Anm. 150], S. 107), ist damit die Grundlage entzogen. Bereits NAGLER (Anm. 58), S. 723 geißelte die Behauptung einer absoluten Strafpflichtigkeit von Verbrechen als einen starren „Doktrinarismus“, der das Vorrecht „,des Unfehlbarkeitsdünkels der Studierstube“ bleibe und in der Praxis nie eine Rolle gespielt habe.

157 Allerdings ist die seit geraumer Zeit zu beobachtende „Viktimophilie“ (WEIGEND [Anm. 124], S. 16) aus anderen Gründen problematisch: Sie leistet dem Missverständnis Vorschub, dass es im Strafrecht und Strafverfahrensrecht primär um die Aufarbeitung des Täter-Opfer-Konflikts und nicht - wie es tatsächlich der Fall ist - um eine Auseinandersetzung zwischen der Rechtsgemeinschaft und dem Tatverdächtigen geht. Dadurch verwischt sie nicht zuletzt auch die Abgrenzung des Strafrechts zum Zivilrecht (näher WELKE [Anm. 124], S. 270 ff.).

158 Im Wesentlichen wie hier bereits NAGLER (Anm. 58), S. 585 ff., 721 ff.

159 Abwegig ist es daher, wenn HeinZ STEINERT, Gerechtigkeit als der Versuch, Herrschaft zu kontrollieren und das Problem der staatlich organisierten Zufügung von Schmerz, in: Ota Weinberger (Hrsg.), Internationales Jahrbuch für Rechtsphilosophie und Gesetzgebung, 1989, S. 341, 344 die „reine Form der Strafe“ in dem Verhalten des Herrn erblickt, ,der in einem plötzlichen Wutanfall ein Tier oder einen Sklaven prügelt". 
Pflichterfuillung gibt - zuwidergehandelt hat, muss er es sich gefallen lassen, dass auf seine Kosten die Unauflöslichkeit des Zusammenhanges von Freiheitsgenuss und Mitwirkungspflichterfüllung bestätigt wird. Der Name des bestätigenden Aktes lautet: Strafe. ${ }^{160}$

Das Moment der Schmerzzufügung ist einer derart verstandenen Strafe immanent. Die Strafe muss ein Übel sein, ,wenn sie als Zeichen für die fortdauernde Gültigkeit der Norm nicht nur registriert, sondern ihre Botschaft auch geglaubt werden soll." ${ }^{161}$ Indem der bestrafte Bürger nach Maßgabe des Ausmaßes seiner Pflichtverletzung zur Stärkung dieses Glaubens herangezogen wird, wird demonstriert, dass jemand, der den bestehenden Zustand realer Freiheitlichkeit angreift, sich dadurch selbst um einen Teil seiner Freiheit bringt. Deshalb repräsentieren die Strafmittel jeweils spiegelbildlich jenen Vorteil, der nach neuzeitlicher Grundüberzeugung die Begründung einer Rechtsordnung legitimiert: den Zugewinn an Handlungsoptionen. ${ }^{162}$ Sowohl die „Entziehung der äußern Welt mit der Befriedigung, die sie gewährt" ${ }^{\text {"163 }}$ durch die Freiheitsstrafe als auch die zwangsweise Entziehung von Vermögenswerten durch die Geldstrafe sind darauf angelegt, den Handlungsspielraum des Delinquenten zu reduzieren. Freilich mag das Moment der realen Zwangsausübung in weitem Umfang hinter der zeichenhaften Stigmatisierung des Täters zurücktreten. Je sicherer eine Gesellschaft ihrer selbst ist, desto eher nimmt sie das Verbrechen als ein „Unfestes und Isoliertes“ wahr und desto milder können dann auch die Strafen ausfallen. ${ }^{164}$ Der sozialen und kulturellen Evolution

160 Ähnlich Henkel (Anm. 156), S. 412; ARthur KAUfMAnN, Subsidiaritätsprinzip und Strafrecht, in: Claus Roxin u.a. (Hrsg.), Grundfragen der gesamten Strafrechtswissenschaft, Festschrift für Heinrich Henkel zum 70. Geburtstag, 1974, S. 89, 106; RoXIN (Anm. 152), S. 385, der diesen Gedanken in seinen späteren Arbeiten jedoch nicht weiter verfolgt hat. - $\mathrm{Zu}$ weitgehend, da auf eine unzulässige Ethisierung des Rechts hinauslaufend, ist es, wenn CHRISTIAN LAUE, Symbolische Wiedergutmachung, 1999, S. 70 zur Wiedergutmachung der sozialen Störung einen „Akt der Identifikation“ des Täters mit der Rechtsgemeinschaft verlangt.

161 IngEbORG PuPPE, Strafrecht als Kommunikation. Leistungen und Gefahren eines neuen Paradigmas in der Strafrechtsdogmatik, in: Erich Samson u.a. (Hrsg.), Festschrift für Gerald Grünwald zum 70. Geburtstag, 1999, S. 469, 479; ähnlich GÜNTHER JAKOBS, Staatliche Strafe: Bedeutung und Zweck, 2004, S. 329; DERS., Rechtszwang und Personalität, 2008, S. 33; BAurmann (Anm. 73), S. 371 ff.; José Luis DieZ RipPOLÉS, Symbolisches Strafrecht und die Wirkungen der Strafe, ZStW 113 (2001), S. 516, 524; Dölling (Anm. 83), S. 15 ff.; Koller (Anm. 38), S. 71.

162 URs KindHÄUSER, Gefährdung als Straftat, 1989, S. 157.

163 STAHL (Anm. 1), Bd. II/2, S. 698.

164 So bereits Hegel (Anm. 109), \218 Z (S. 373); ausführlich dazu MÜLlER-TUCKFELD (Anm. 72), S. 280 ff. Ebenso NAGLER (Anm. 58), S. 615 f. - Insofern mag man mit WOLFGANG SCHILD, Ende und Zukunft des Strafrechts, ARSP 70 (1984), S. 72, 104 davon sprechen, dass es gerade der absolute Strafbegriff ist, der die (auf die konkrete Bestimmung der Art und des Grades des Strafübels beschränkte) Wahrheit der relativen Straftheorien begründet. 
ist dabei ein weites Feld eröffnet. ${ }^{165}$ Eine gewisse Drastik der strafenden Sanktion ist aber unverzichtbar; denn anders lässt sich die Konnexität von Mitwirkungspflichterfüllung und Freiheitsgenuss nicht überzeugend vermitteln.

Der Gesichtspunkt der sogenannten Spezialprävention (insbesondere in ihrer Resozialisierungskomponente) hat der hier skizzierten Konzeption zufolge ,innerhalb des staatlichen Strafens“, nicht aber auf der Begründungsebene seinen Platz: ${ }^{166}$ Die Spezialprävention hat vorrangig die Strafvollstreckung zu prägen. ${ }^{167}$ Eine Rechtsgemeinschaft, die den Täter im Akt der Bestrafung in seiner Bürgerrolle anspricht, muss auch den Vollzug dieser Strafe in Respekt vor dem Bürgerstatus des Täters ausgestalten. Gerade weil der Täter Bürger ist und bleibt, hat er deshalb einen Anspruch darauf, dass ihm - soweit erforderlich dazu verholfen wird, seine Primärpflicht zu aktiver Loyalität in Zukunft ordnungsgemäß erfüllen zu können; ${ }^{168}$ deshalb muss der Strafvollzug auch eine „,chanceneröffnend-soziale Seite“ aufweisen, ${ }^{169}$ dem Täter also nach Möglich-

165 Eindringlich HeIKe Jung, Sanktionensysteme und Menschenrechte, 1992, S. 31 ff. (unter Rückgriff auf die Zivilisationstheorie von NORBERT ELIAS); ferner NiKOLAOS ANDROUlakis, Über den Primat der Strafe, ZStW 108 (1996), S. 300, 314 ff., insbesondere S. 320, und WOLFGANG FRISCH, Maßstäbe der Tatproportionalität und Veränderungen des Sanktionenniveaus, in: ders. u.a. (Hrsg.), Tatproportionalität. Normative und empirische Aspekte einer tatproportionalen Strafzumessung, 2003, S. 155, $179 \mathrm{ff}$. - RAINER Keller, Zur Wahrnehmung des Schadens, in: Klaus Lüderssen (Hrsg.), Aufgeklärte Kriminalpolitik oder Kampf gegen das Böse?, Bd. 1, 1998, S. 281, 292 weist darauf hin, dass selbst KANTS spiegelnde Wiedervergeltung ein soziales Deutungsmuster impliziere, nämlich ,die Annahme, der Unwert der Tat sei im gegenständlichen Schaden verkörpert“. Dies sei zu KANTS Zeiten Teil der Lebenswelt gewesen.

166 SCHMIDHÄUSER (Anm. 17), Strafrecht Allgemeiner Teil, 3/17.

167 Die Vorschrift des $\int 46$ Abs. 1 Satz 2 StGB gebietet nichts Abweichendes; dazu WOLFGANG FRISCH, Strafkonzept, Strafzumessungstatsachen und Maßstäbe der Strafzumessung in der Rechtsprechung des Bundesgerichtshofs, in: Claus Wilhelm Canaris u.a. (Hrsg.), 50 Jahre Bundesgerichtshof. Festgabe aus der Wissenschaft, Bd. IV, 2000, S. 269, 308.

168 Ähnlich Wolfgang Schild, Strafe - Vergeltung oder Gnade?, SchZStrR 99 (1982), S. 364, 380 ff.; DERS. (Anm. 152), S. 287, 308; HANS-HARTMANN VON SCHLOTHEIM, Sinn und Zweck des Strafens und der Strafe, MschrKrim 50 (1967), S. 1, 4, 12. - Nichts anderes besagt die ,soziale Verantwortung“, von der $\$ 2$ Satz 1 StrVollzG spricht. Entgegen den Bedenken des Alternativentwurfs (JÜRGEN BAUMANN u.a., Alternativentwurf eines Strafvollzugsgesetzes, 1973, S. 55) liegt darin keineswegs eine unzulässige Moralisierung des Strafvollzugs, sondern geradezu eine strafbegriffliche Selbstverständlichkeit.

169 KÖHLER (Anm. 38), Strafrecht Allgemeiner Teil, S. 50. - In der Sache ganz ähnlich leitet das Bundesverfassungsgericht den Grundsatz der Resozialisierung aus der Menschenwürde in Verbindung mit dem Sozialstaatsprinzip ab (BVerfGE 35, S. 202, 235 f.). 
keit mehr Handlungskompetenz und soziale Teilhabe vermitteln. ${ }^{170}$ Nach einer treffenden Bemerkung NOLLS kann die Rechtsgemeinschaft nicht erwarten, dass der Delinquent seine Verantwortung ihr gegenüber erkennt und übernimmt, wenn sie ihre Verantwortung ihm gegenüber ablehnt. ${ }^{171}$ Eingedenk seiner fortbestehenden Bürgerrolle ist freilich auch der Täter selbst an sich dazu verpflichtet, an seiner Resozialisierung mitzuwirken. ${ }^{172}$ Dass $\$ 4$ I StVollzG davon absieht, die Erfüllung dieser Pflicht disziplinarrechtlich zu erzwingen, lässt sich auf pragmatische Gründe stützen; ,gelingende Lernprozesse zu installieren, geht nicht ohne die Zustimmung und freiwillige Mitwirkung des Gefangenen." ${ }^{173}$

Damit sind die Grundzüge einer Vergeltungstheorie der Strafe skizziert, die, wie ich glaube, den herkömmlichen Einwänden gegen dieses Begründungsmodell nicht ausgesetzt ist. Diese Konzeption steht der präventionstheoretischen Auffassung, zumal der Lehre von der positiven Generalprävention, weitaus näher, als es der Mythos von der Unversöhnlichkeit beider Positionen behauptet. ${ }^{174}$ Sie ist weit davon entfernt, ,in zweckgelöster Majestät in den Grundrechten der Menschen herum[zufuhrwerken]. ${ }^{1175}$ Nicht anders als den

170 Dass die Vollstreckung der strafrechtlichen Sanktionen primär die Aufgabe der „Herstellung von Partizipationschancen" hat, ist insbesondere von CALLIESS herausgearbeitet worden (ROLF-Peter CAlliess, Theorie der Strafe im demokratischen und sozialen Rechtsstaat. Ein Beitrag zur strafrechtsdogmatischen Grundlagendiskussion, 1974, S. 64, 155 ff.).

171 Noll (Anm. 83), S. 26.

172 Dies wird verbreitet bestritten. Exemplarisch BAUMANN u.a. (Anm. 168), S. 59; zuletzt SANDRA MÜlleR-STEINHAUER, Autonomie und Besserung im Strafvollzug. Resozialisierung auf Basis der Rechtsphilosophie Immanuel Kants, 2001, S. $234 \mathrm{ff}$.

173 Rolf-Peter Calliess, Die Strafzwecke und ihre Funktion. Straftheorie oder dialogische Strafrechtstheorie als Bezugsrahmen, in: Guido Britz u.a. (Hrsg.), Grundfragen staatlichen Strafens. Festschrift für Heinz Müller-Dietz zum 70. Geburtstag, 2001, S. 99, 116. Sachlich übereinstimmend DiETER DÖLling, Zur spezialpräventiven Aufgabe des Strafrechts, in: ders. (Hrsg.), Jus humanum. Grundlagen des Rechts und Strafrecht. Festschrift für Ernst-Joachim Lampe zum 70. Geburtstag, 2003, S. 597, 607 f.; JAKOBS (Anm. 61), 1/47; HeINZ SCHÖCH, Verstehen, Erklären, Bestrafen? Vergangenes und Aktuelles zur ,gesamten Strafrechtswissenschaft“, in: Ulrich Immenga (Hrsg.), Rechtswissenschaft und Rechtsentwicklung, 1980, S. 305, 318; HANS SCHULTZ, Abschied vom Strafrecht?, ZStW 92 (1980), S. 611, 621. - Vollzugslockerungen sowie die vorzeitige Entlassung dürfen einem Gefangenen, der sich allen Resozialisierungsangeboten hartnäckig verweigert, hingegen durchaus verweigert werden (Alexander BÖHM, Strafvollzug, 3. Aufl. 2003, Rn. 15 m. w. N.; a. A. zuletzt MÜlleR-STEINHAUeR [Anm. 172], S. 268).

174 Zuletzt ist dieser Mythos beschworen worden von MARCUS BASTELBERGER, Die Legitimität des Strafrechts und der moralische Staat, 2006, S. 52 ff., $117 \mathrm{ff}$.

175 So der Vorwurf Winfried HASSEMERS, Gefahrenabwehr durch Strafrecht - Eine Antwort auf aktuelle Sicherheitsbedürfnisse?, WestEnd 2006, S. 75, 77 gegen die Vergeltungslehren. HASSEMER spielt darin an auf ReINHART MAURACH, Deutsches Strafrecht (Allgemeiner Teil), 4. Aufl. 1971, S. 77. 
Präventionslehren geht es vielmehr auch ihr um die Erhaltung der gesellschaftlichen Ordnung. Unterschiedlich sind jedoch die Begründungsmodelle, mit denen beide Auffassungen die erhaltungswürdigen Merkmale dieser Ordnung auf den Begriff zu bringen suchen. Aus Sicht der Präventionstheorien dient das Strafrecht - mit HASSEMER gesprochen - der „Verbesserung der Welt““ ${ }^{176}$ Es ist ein Instrument des gesellschaftlichen Interessenschutzes; vor diesem Hintergrund geht es darum, aus der durch die Straftat herbeigeführten suboptimalen Situation das im Hinblick auf das weitere soziale Leben Beste zu machen. Nach hiesigem Verständnis hingegen ist der Rechtsgrund der Strafe ,allein das Verbrechen selbst " ${ }^{177}$, allerdings unter dem Blickwinkel seiner Bedeutung nicht nur für das konkrete Opfer, sondern für die betroffene Rechtsgemeinschaft als Ganze. Das von mir vorgeschlagene Begründungsmodell mythologisiert die Strafe nicht, aber es verfällt auch nicht dem gegenteiligen Irrglauben, die Aufgabe der Straflegitimation lasse sich auf den Status eines technischen Optimierungsproblems herunterrechnen. Sein Grundgedanke ist von größter Einfachheit: Den Täter trifft eine rechtliche Mitverantwortung für den Fortbestand des freiheitlichen Zustandes, innerhalb dessen er lebt. An dieser Mitverantwortung wird er in der Strafe festgehalten, indem auf seine Kosten die Wechselbezüglichkeit von Mitwirkungspflichterfüllung und Freiheitsgenuss bestätigt wird. Legitimes Strafrecht ist definitionsgemäß Bürgerstrafrecht; es gibt kein anderes. ${ }^{178}$

176 HASSEMER (Anm. 175), S. 75.

177 Hugo HälsCHNER, Das gemeine deutsche Strafrecht, 1881, S. 31.

178 Zur hiesigen Kritik an der Kategorie eines Feindstrafrechts: PAWLIK (Anm. 103), S. $38 \mathrm{ff}$. 
